\title{
Cranberry proanthocyanidins inhibit esophageal adenocarcinoma in vitro and in vivo through pleiotropic cell death induction and PI3K/AKT/mTOR inactivation
}

\author{
Laura A. Kresty ${ }^{1}$, Katherine M. Weh ${ }^{1}$, Bree Zeyzus-Johns ${ }^{1}$, Laura N. Perez ${ }^{1}$ and \\ Amy B. Howell ${ }^{2}$ \\ ${ }^{1}$ Division of Hematology and Oncology, Department of Medicine, Medical College of Wisconsin, Milwaukee, Wisconsin, USA \\ 2 Marucci Center for Blueberry and Cranberry Research, Rutgers University, Chatsworth, New Jersey, USA \\ Correspondence to: Laura A. Kresty, email: Lkresty@mcw.edu \\ Keywords: autophagy, cranberry proanthocyanidins, esophageal adenocarcinoma, bile acid, PI3K/AKT/mTOR \\ Received: July 22, $2015 \quad$ Accepted: August 19, $2015 \quad$ Published: September 10, 2015
}

This is an open-access article distributed under the terms of the Creative Commons Attribution License, which permits unrestricted use, distribution, and reproduction in any medium, provided the original author and source are credited.

\section{ABSTRACT}

Cranberries are rich in bioactive constituents known to improve urinary tract health and more recent evidence supports cranberries possess cancer inhibitory properties. However, mechanisms of cancer inhibition by cranberries remain to be elucidated, particularly in vivo. Properties of a purified cranberry-derived proanthocyanidin extract (C-PAC) were investigated utilizing acid-sensitive and acid-resistant human esophageal adenocarcinoma (EAC) cell lines and esophageal tumor xenografts in athymic NU/NU mice. C-PAC induced caspase-independent cell death mainly via autophagy and low levels of apoptosis in acid-sensitive JHAD1 and OE33 cells, but resulted in cellular necrosis in acid-resistant OE19 cells. Similarly, C-PAC induced necrosis in JHAD1 cells pushed to acid-resistance via repeated exposures to an acidified bile cocktail. C-PAC associated cell death involved PI3K/ AKT/mTOR inactivation, pro-apoptotic protein induction (BAX, BAK1, deamidated BCL-XL, Cytochrome C, PARP), modulation of MAPKs (P-P38/P-JNK) and $G_{2-}$ M cell cycle arrest in vitro. Importantly, oral delivery of C-PAC significantly inhibited OE19 tumor xenograft growth via modulation of AKT/mTOR/MAPK signaling and induction of the autophagic form of LC3B supporting in vivo efficacy against EAC for the first time. C-PAC is a potent inducer of EAC cell death and is efficacious in vivo at non-toxic behaviorally achievable concentrations, holding promise for preventive or therapeutic interventions in cohorts at increased risk for EAC, a rapidly rising and extremely deadly malignancy.

\section{INTRODUCTION}

Esophageal adenocarcinoma (EAC) rates have increased over $500 \%$ during the last thirty years identifying EAC as the major histologic subtype of esophageal cancer and the fastest increasing of all cancer types in the US [1,2]. In 2015, 16,980 new incident cases and 15,590 deaths due to esophageal cancer are estimated, representing the $7^{\text {th }}$ leading cause of cancer related deaths among US males [3]. Mortality and incidence statistics closely parallel one another reflecting poor survival due to ineffective options for screening, prevention and treatment coupled with late stage diagnosis. The precise reasons for the rapid increase in EAC and the only known precursor lesion, Barrett's esophagus (BE), are still being unraveled. However, persistent, symptomatic, reflux of gastric and duodenal contents, known as gastroesophageal reflux disease (GERD), have long been known to correlate with the development of BE and EAC $[4,5]$. Heartburn is the primary symptom of GERD and is estimated to impact 60 million Americans [4]. In addition, obesity is reported to impart a 2 to 2.5 -fold increase risk for EAC and a 1.5 to 2 -fold increase risk for GERD [5]. Thus, there is a large population at elevated risk for BE and EAC, illustrating the potential global health significance of this growing problem. Other risk factors linked to the development of 
EAC include specific nutritional factors, overall dietary patterns, animal-based diets and the presence of hiatal hernia [6-8]. Plant-based diets rich in fruits, vegetables and fiber have generally been associated with EAC risk reduction [6] leading our laboratory to evaluate well characterized purified plant-derived extracts as potential inhibitors.

The urinary tract health benefits of cranberries are attributable to the unique A-type linkages in cranberry proanthocyanidins (C-PACs) which prevent adhesion of p-fimbriated uropathogenic E. coli [9-14]. More recently, cranberries have been reported to possess cancer inhibitory properties based on a large number of in vitro studies utilizing diverse cell lines of prostate, breast, cervical, ovarian, oral, stomach, bladder, neuroblastoma, lung and esophageal origin [15-23]. However, there is limited mechanistic information regarding the ability of cranberry constituents to inhibit cancers, especially in vivo. A small number of xenograft studies delivering cranberry extracts by intraperitoneal injections have shown positive results, supporting that direct administration increases tumor latency and inhibits growth of gastric, colon, prostate, lymphoma and glioblastoma cancer cells [15, 21-23]. To our knowledge only two in vivo studies report cancer-linked inhibitory effects following oral delivery of cranberry products. Boateng et al. indicated that $20 \%$ cranberry juice reduces azoxymethane-induced aberrant crypt foci [24]; whereas, Prasain and colleagues reported that cranberry juice inhibits nitrosamine-induced urinary bladder cancer development by $38 \%$ [25], but lacked any mechanistic explanation.

In this series of studies, we sought to investigate mechanisms associated with the cancer inhibitory potential of C-PAC, a well characterized proanthocyanidin-rich cranberry extract, utilizing a panel of authenticated EAC cell lines and conducting parallel molecular evaluations in the first in vivo study focused on C-PAC inhibition of EAC. Clinical and preclinical research efforts support that alterations in the susceptibility to cell death underlie neoplastic progression of Barrett's to EAC. In addition, acid refluxant is linked to alterations of inflammatory molecules, NF-kB signaling, PI3K/AKT/mTOR activation and MAPK signaling, ultimately resulting in an apoptosis resistant phenotype [26-31]. Targeting these pathways is logical for the prevention of esophageal cancer and potentially other cancers in which inflammation and aberrant cell death pathways provide a growth advantage and support resistance to treatment.

\section{RESULTS}

\section{C-PAC induced G2-M cell cycle arrest and cell line specific S-phase delay accompanied by morphological changes consistent with cell death induction}

We previously determined the $\mathrm{IC}_{50}$ of C-PAC to be $50-100 \mu \mathrm{g} / \mathrm{ml}$ based on WST-1 and BrdU in vitro assays conducted in EAC (JHAD1 and OE19), lung (NCI-H460, misidentified as SEG-1) and colon (SW460, misidentified as BIC-1) cancer cell lines [16-18]. The latter two cell lines were accepted to be EAC cell lines for decades, but in 2010 DNA finger printing confirmed SEG-1 and BIC1 to be of lung and colon origin, respectively [32]. The present study is the first to utilize authenticated human EAC cell lines and EAC xenografts to investigate cancer inhibitory mechanisms associated with C-PAC treatment. As illustrated in Figure 1A-1D and Supplemental Figure 1S, flow cytometric results from PI staining alone showed that C-PAC treatment of EAC cells resulted in a dose and time-dependent effect on phase of cell cycle. C-PAC [50 and $100 \mu \mathrm{g} / \mathrm{ml}$ ] treatment of OE19 cells significantly decreased the percentage of $G_{1}$ cells and significantly increased the percentage of cells at the $\mathrm{G}_{2}-\mathrm{M}$ checkpoint. A similar significant pattern of reduced $\mathrm{G}_{1}$ and increased accumulation of cells at $\mathrm{G}_{2}-\mathrm{M}$ was noted for C-PAC treated OE33 and JHAD1 EAC cells (Supplemental Figure 1S). Additionally, C-PAC [50 and $100 \mu \mathrm{g} / \mathrm{ml}$ ] treatment of OE19 cell lines resulted in significantly increased S-phase fraction based upon PI staining alone (Figure $1 \mathrm{~A}$ and 1C); thus, PI in combination with S-phase specific BrdU staining was conducted to assess S-phase distribution. BrdU incorporation plots by treatment are shown in Figure 1B for OE19 treated cells and Supplemental Figure 1S and Figure 1C for OE33 cells. Vehicle treated OE19 cells exhibited the highest intensity of BrdU staining corresponding to the highest proliferative rates, $66.9 \%$ compared to significantly reduced levels $(14.4 \%$ and $0.4 \% \mathrm{BrdU}$ ) in OE19 cells treated with 50 and $100 \mu \mathrm{g} /$ $\mathrm{ml}$ C-PAC, respectively. C-PAC significantly inhibited BrdU incorporation in a dose-responsive manner; slow proliferating cells represented $9.4 \%$ of the S-phase fraction in vehicle treated OE19 cells compared to $29 \%$ and $78 \%$ in 50 and $100 \mu \mathrm{g} / \mathrm{ml} \mathrm{C-PAC}$ treated cells, respectively. Similarly, the percentage of OE33 cells in S-phase were significantly reduced by C-PAC, but without an S-phase delay (Supplemental Figure 1S and Figure 1C). Furthermore, DNA histogram results (Figure 1C) revealed that C-PAC induced a significant sub $\mathrm{G}_{1}$ peak $(17.3 \%)$ characteristic of late apoptosis compared to only $1.8 \%$ in vehicle treated cells. Figure 1D depicts C-PAC induced changes in EAC cell morphology and illustrates reduced viability post-treatment as previously reported [18]. 
Characteristic features of cell death evident following C-PAC treatment included nuclear fragmentation and clumping, cellular blebbing, apoptotic residual bodies, but also cytoplasmic swelling with intact membranes and increased cytoplasmic vacuolization in JHAD1 and OE33, leading us to evaluate autophagy linked cell death. Cellular necrosis was evident given increasing concentrations of C-PAC, particularly in OE19 cells.

\section{C-PAC differentially induced cell death based on cell line acid resistance}

Annexin V-FITC/PI staining of C-PAC [50 and 100 $\mu \mathrm{g} / \mathrm{ml}]$ treated OE19, OE33 and JHAD1 cells harvested at 24 and 48 hours permitted assessment of cell death induction via apoptosis and necrosis as summarized in Figure 2A-2D and Supplemental Figure 1S, C. C-PACs $[100 \mu \mathrm{g} / \mathrm{ml}]$ main effect in OE19 cells was markedly induced necrosis, $36 \%$ or 5.8 -fold at 24 hours and $40 \%$ or 8.2 -fold at 48 hours $(P<0.05)$; yet, only mild apoptosis was induced $(12.3 \%, P<0.05)$. C-PAC [50 $\mu \mathrm{g} /$ $\mathrm{ml}$ ] significantly induced apoptosis and to a lesser extent necrosis in OE33 cells at 24 and 48 hours post-treatment. C-PAC $[50 \mu \mathrm{g} / \mathrm{ml}]$ induced significant apoptosis in JHAD1 cells at 24 and 48 hours.

We evaluated how EAC cell lines responded to a single 5 minute exposure to an acidified bile cocktail $(\mathrm{pH}=4)$. Figure 2E shows that JHAD1 and OE33 cells were acid sensitive responding with rapid cell death (50 and $40 \%$, respectively) 24 hours post-treatment. In sharp contrast, bile cocktail treated OE19 cells did not result in significant cell death induction, supporting inherent acid resistance compared to JHAD1 and OE33 cells. Next, JHAD1 and OE33 cells were repeatedly treated with the acidified bile cocktail every other day for 7.5 minutes mimicking multiple reflux episodes, as frequently occurs in patients with GERD. Following the fifth treatment both cell lines developed resistance based upon growth and confluency compared to naïve cells. Subsequently, acid sensitive or naïve JHAD1 cells and JHAD1 acid resistant (AR) cells were treated with C-PAC and evaluated for
A

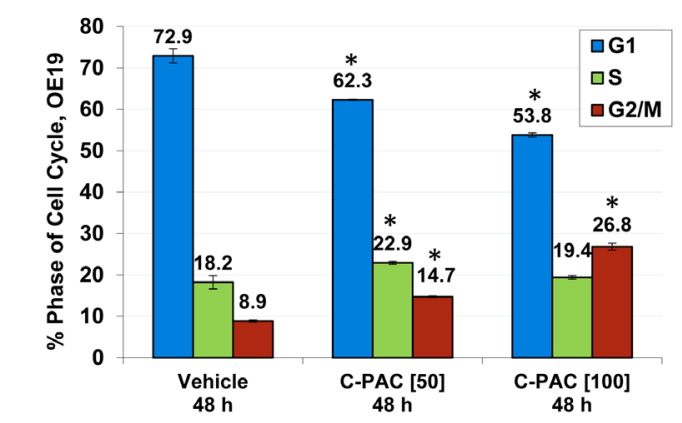

C

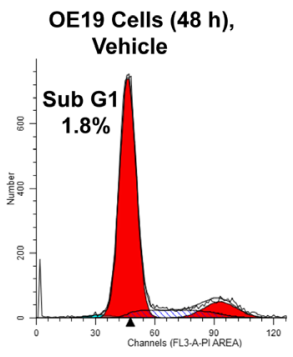

B
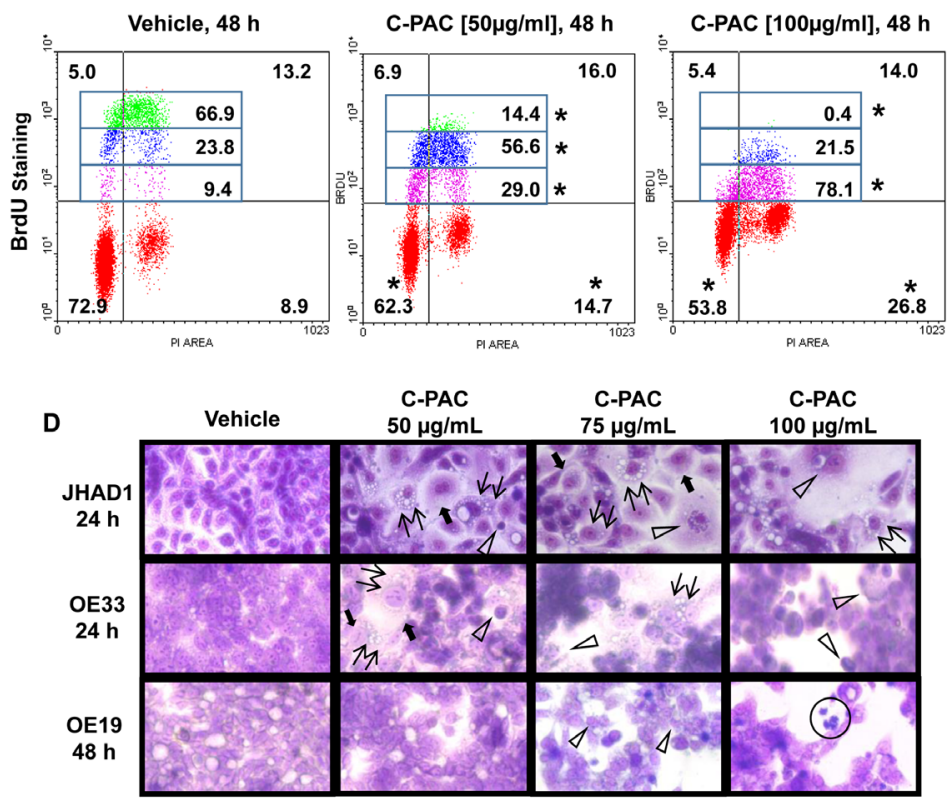

Figure 1: Effect of C-PAC on cell cycle distribution of EAC cells. EAC cells were treated with C-PAC [50 or $100 \mu \mathrm{g} / \mathrm{ml}]$ for 24 and 48 hours, stained with PI alone or PI in combination with BrdU to determine cell-cycle phase and evaluate S-phase distribution. Cells were analyzed in triplicate for each condition with representative data shown as mean percentages + SEM. ${ }^{*} P<0.05$ indicates a significant difference between C-PAC and vehicle treated cells, two-tailed Students $t$-test. A. C-PAC treatment significantly altered phase of cell cycle distribution in OE19, JHAD1 and OE33 cells (Supplemental Figure 1S, A and B). B. C-PAC induced a significant and dosedependent S-phase delay in OE19 cells based on combined PI/BrdU staining. The upper left and upper right quadrants of each treatment panel represent early and late S-phase, respectively. The S-phase fraction was further quantitated for the intensity of BrdU incorporation by tertiles to examine differences in proliferative potential. C-PAC reduced BrdU incorporation as indicated by compression of the Y-axis intensity values $\left({ }^{*} P<0.05\right)$. C-PAC treatment of OE33 cells did not result in an S-phase delay (Supplemental Figure 1S, A-C). C. C-PAC treatment decreased cells in $\mathrm{G}_{1}$, increased cells in $\mathrm{G}_{2}$ and caused a significant increase on the sub- $\mathrm{G}_{1}$ peak indicative of late apoptosis. D. C-PAC treatment altered EAC cellular morphology. Double arrows indicate formation of vacuoles and solid arrows show cytoplasmic swelling with intact membranes associated with induction of autophagic vesicles; open arrowheads mark apoptotic cells. Cellular necrosis is also evident (circled cells) given increasing concentrations of C-PAC, particularly in OE19 cells (All images, 400X). 
A

\begin{tabular}{|c|c|c|}
\hline Cell Line [Treatment], Hours & $\begin{array}{l}\text { \% Apoptosis } \\
\text { (Fold Change) }\end{array}$ & $\begin{array}{l}\% \text { Necrosis } \\
\text { (Fold Change) }\end{array}$ \\
\hline OE19 $[50 \mu \mathrm{g} / \mathrm{ml}$ C-PAC], $24 \mathrm{~h}$ & $13.5 \% \quad(1.2$-Fold Inc $)$ & $9.5 \% \quad$ (4.5-Fold Inc) \\
\hline OE19 $[50 \mu \mathrm{g} / \mathrm{ml}$ C-PAC], $48 \mathrm{~h}$ & $8.0 \% \quad$ (1.1-Fold Inc) & $11.2 \%(1.6-$ Fold Inc) * \\
\hline OE19 $[100 \mu \mathrm{g} / \mathrm{ml} \mathrm{C-PAC}], 24 \mathrm{~h}$ & $13.6 \% \quad(1.4-$-Fold Inc) & $35.8 \%(5.8$-Fold Inc) * \\
\hline OE19 $[100 \mu \mathrm{g} / \mathrm{ml} \mathrm{C-PAC}], 48 \mathrm{~h}$ & $12.3 \%(1.4-$-Fold $\operatorname{lnc}) *$ & $39.6 \%(8.2$-Fold Inc) * \\
\hline JHAD1 $[50 \mu \mathrm{g} / \mathrm{ml} \mathrm{C-PAC],} 24 \mathrm{~h}$ & $10.7 \%(1.8$-Fold $\operatorname{lnc}) *$ & $0.5 \% \quad(1.7$-Fold Inc $)$ \\
\hline JHAD1 [50 $\mu \mathrm{g} / \mathrm{ml} \mathrm{C-PAC],} 48 \mathrm{~h}$ & $14.6 \%(3.3$-Fold Inc $) *$ & $0.6 \%(4.4-$-Fold Inc) $*$ \\
\hline JHAD1 [1X Bile Acid, $0.25 \mathrm{mM}$ ], $24 \mathrm{~h}$ & $89.41 \%(9.6-$-Fold Inc) * & $1.9 \% \quad(3.5-$ Fold Inc) \\
\hline JHAD1-AR [Bile Acid, $0.25 \mathrm{mM}$ ], $24 \mathrm{~h}$ & $14.1 \%$ (1.5-fold Inc) & $2.2 \% \quad$ (3.8-Fold Inc) \\
\hline JHAD1-AR [Bile Acid + C-PAC], 24 h & $14.4 \%$ (1.5-fold Inc) & $17.5 \%(8.5$-Fold Inc) * \\
\hline OE33 [50 $\mu \mathrm{g} / \mathrm{ml}$ C-PAC], $24 \mathrm{~h}$ & $17.6 \% \quad(1.5$-Fold Inc) * & $6.3 \%(1.5$-Fold Inc) * \\
\hline OE33 $[50 \mu \mathrm{g} / \mathrm{ml}$ C-PAC], $48 \mathrm{~h}$ & $3.3 \%$ (18.4-Fold Dec) * & $9.0 \%(2.0$-Fold Inc) * \\
\hline
\end{tabular}

B
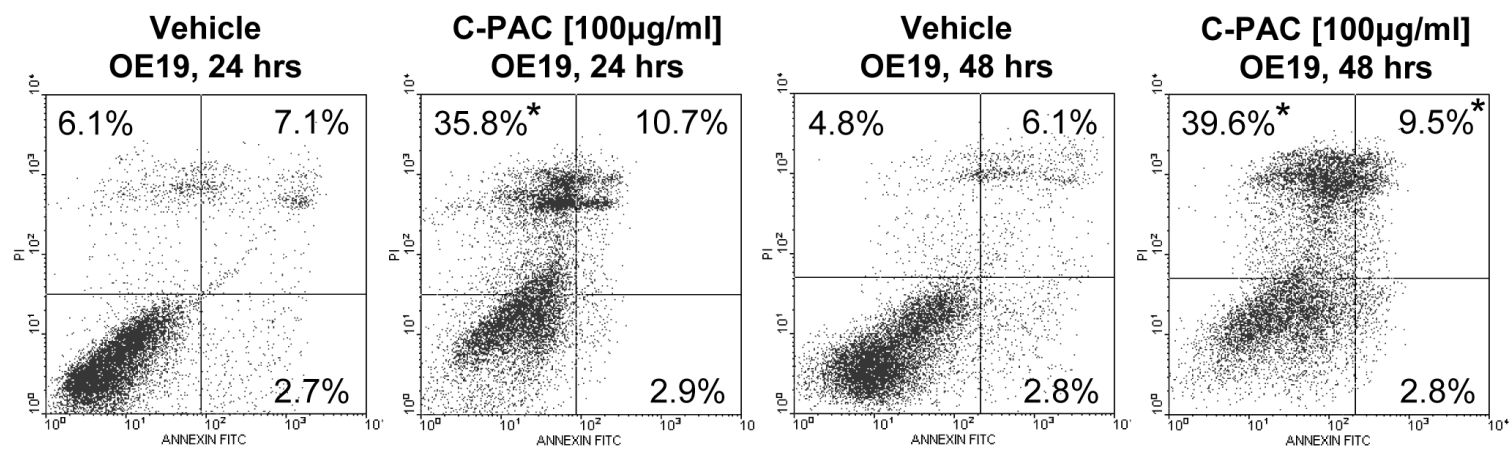

C

Vehicle

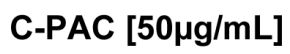

JHAD1, 24 hrs
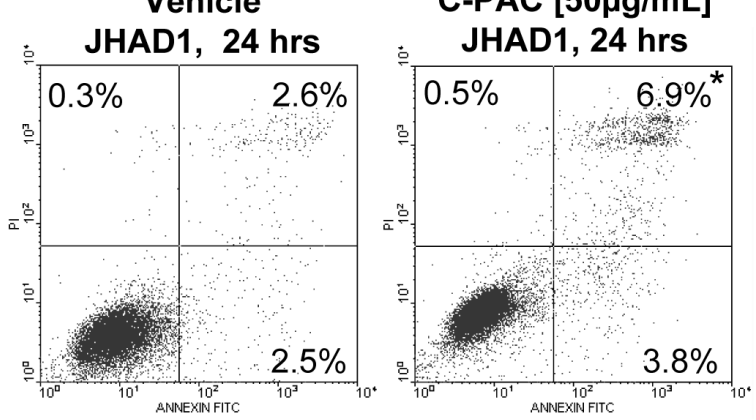

Vehicle

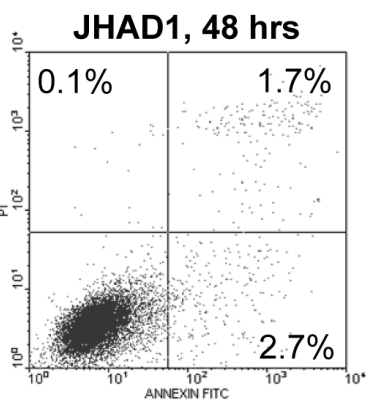

C-PAC $[50 \mu \mathrm{g} / \mathrm{mL}]$

JHAD1, 48 hrs

D

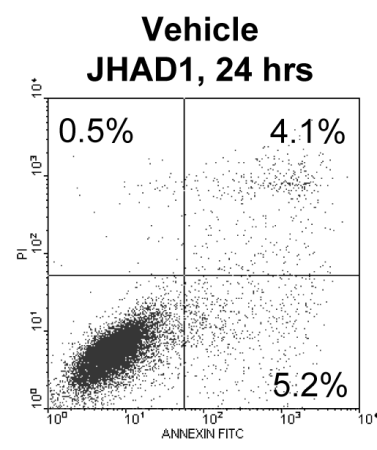

Acidified Bile (1X) JHAD1, 24 hrs

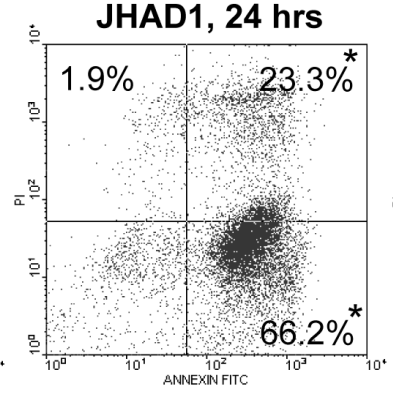

Acidified Bile (1X) JHAD1-AR, 24 hrs
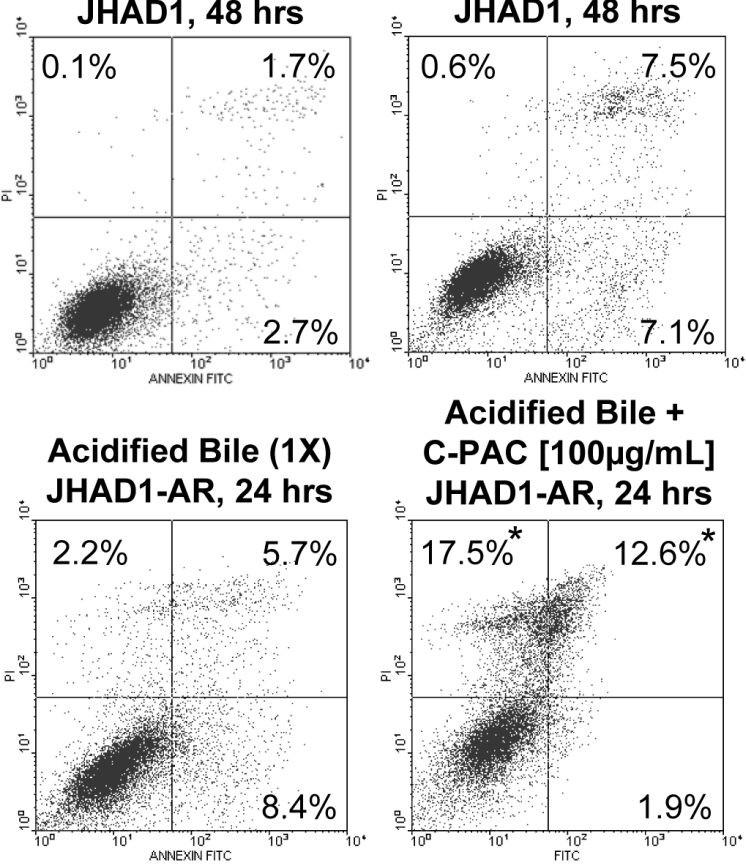

Acidified Bile + C-PAC [100 $\mu \mathrm{g} / \mathrm{mL}]$ JHAD1-AR, 24 hrs

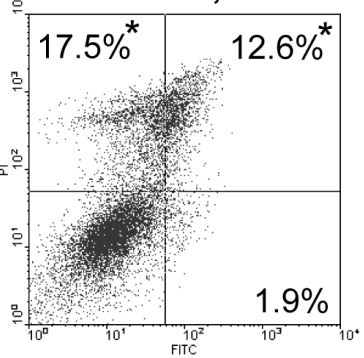




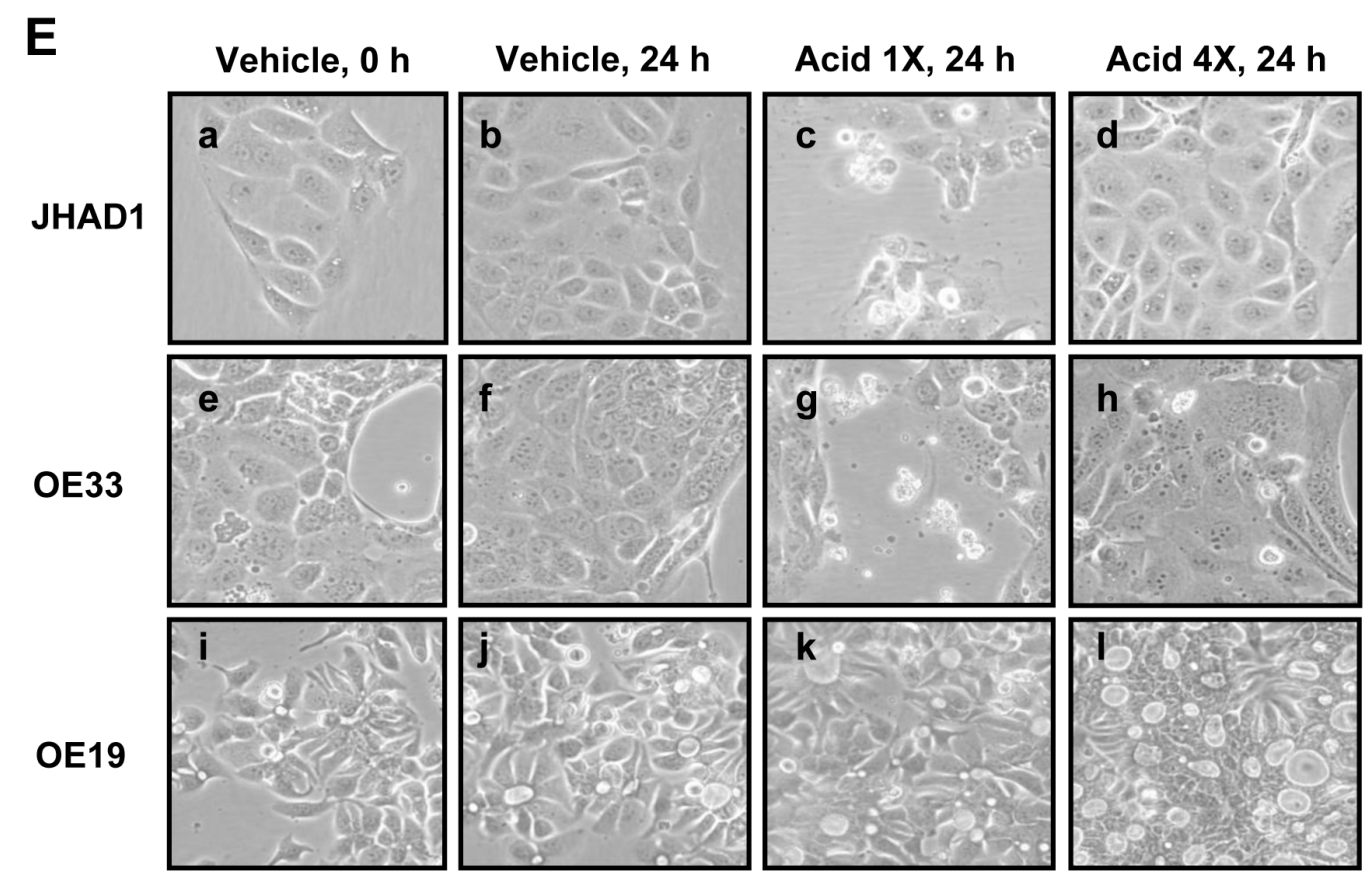

Figure 2: C-PAC differentially induced EAC cell line death based on acid-resistance. EAC cells were treated with C-PAC [50 or $100 \mu \mathrm{g} / \mathrm{ml}$ ] and harvested at 24 or 48 hours post-treatment for assessment of cellular apoptosis and necrosis using Annexin V-FITC staining coupled with flow cytometry. Data are represented as mean values from 3-4 independent samples and the asterisk $(*)$ indicates a significant difference $(P<0.05)$ compared to vehicle treated cells. A. Summarizes the dose dependent and temporal effects of C-PAC on total apoptosis and necrosis induction in OE19, OE33 and naïve as well as acid resistant (AR) JHAD1 cells. Early and late apoptotic events were summed and data presented as a mean percentage of total apoptosis or necrosis with fold change from vehicle cells in parenthesis. B. Representative plots of Annexin V-FITC stained OE19 cells treated with vehicle or C-PAC [100 $\mu \mathrm{g} / \mathrm{ml}]$ for 24 or 48 hours. C. Representative plots of Annexin V-FITC stained JHAD1 cells treated with vehicle or C-PAC [50 $\mu \mathrm{g} / \mathrm{ml}$ ] for 24 or 48 hours. D. Representative plots of Annexin V-FITC stained JHAD1 cells treated one time with an acid bile cocktail (1X), or multiple times (4X) developing acid resistant (AR) JHAD1 cells which were then treated with vehicle or C-PAC [100 $\mu \mathrm{g} / \mathrm{ml}]$ for 24 hours. In B-D, the upper left, upper right and lower left quadrants represent necrotic, late apoptotic and early apoptotic events, respectively. Similarly, Supplemental Figure 1S, D shows C-PAC induced cell death effects in OE33 cells. E. Representative photomicrographs (400X) illustrates that a single exposure to an acidified bile cocktail results in rapid cell death of JHAD1 and OE33 cells (c and g), but not OE19 cells (k). Acid sensitive JHAD1 and OE33 cells become resistant to the acidified bile cocktail with repeated exposure ( $\mathrm{d}$ and $\mathrm{h}$ ).

death inducing effects. Interestingly, upon a single 5 minute acidified bile cocktail treatment naïve JHAD1 cells experienced rapid and significant apoptosis. Early and late apoptosis levels were significantly increased to 59.6 and $3.7 \%$ at $6 \mathrm{hrs} ; 53.7$ and $31.9 \%$ at 12 hours; and 66.2 and $23.2 \%$ at 24 hours, respectively $(P<0.05$ compared to vehicle treated cells). Conversely, when JHAD1-AR cells were acid-pulsed cell death was not significantly induced (Figure 2D); however, C-PAC treatment of JHAD1-AR cells resulted in significantly increased cell death via late apoptosis $(12.6 \%)$ and to a greater magnitude cellular necrosis, $17.5 \%$ or 8.5 -fold, similar to C-PAC induced death in constitutively acid resistant OE19 cells.

\section{C-PAC induced autophagy}

TEM, MDC staining, and specific autophagic proteins were examined next to evaluate $\mathrm{C}-\mathrm{PAC}$ as an inducer of autophagy in EAC cells. TEM, considered the gold standard for autophagy, permitted assessment of C-PAC induced ultrastructural changes in OE19 and JHAD1 cells (Figure 3A). Vehicle treated cells displayed normal morphology characterized by round smoothly outlined appearing nuclei, normally distributed heterochromatin, well defined plasma membrane and preserved cytoplasmic organelles. In contrast, C-PAC treated JHAD1 cells (Figure 3A, b-d) showed cytoplasmic vacuolization and increased early (6 hours) formation of double and single walled autophagic vesicles. Increased autophagy continued in C-PAC treated JHAD1 cells at 24 hours (f-h) with increased electron dense cargo supporting formation of degradative autophagic vacuoles. C-PAC treated OE19 cells exhibited features of cellular necrosis as illustrated in $\mathrm{j}$ ) and $\mathrm{k}$ ) by moderate chromatin clumping and nuclear disintegration, accompanied by loss of plasma membrane integrity and marked loss of cellular contents (k, l), and extra-cytoplasmic cellular debris (o). Cellular blebbing (k) and karyorrhexis (n) are also evident. Photomicrographs in Figure 3B (400 X) further illustrate the rapid changes in cellular morphology following 


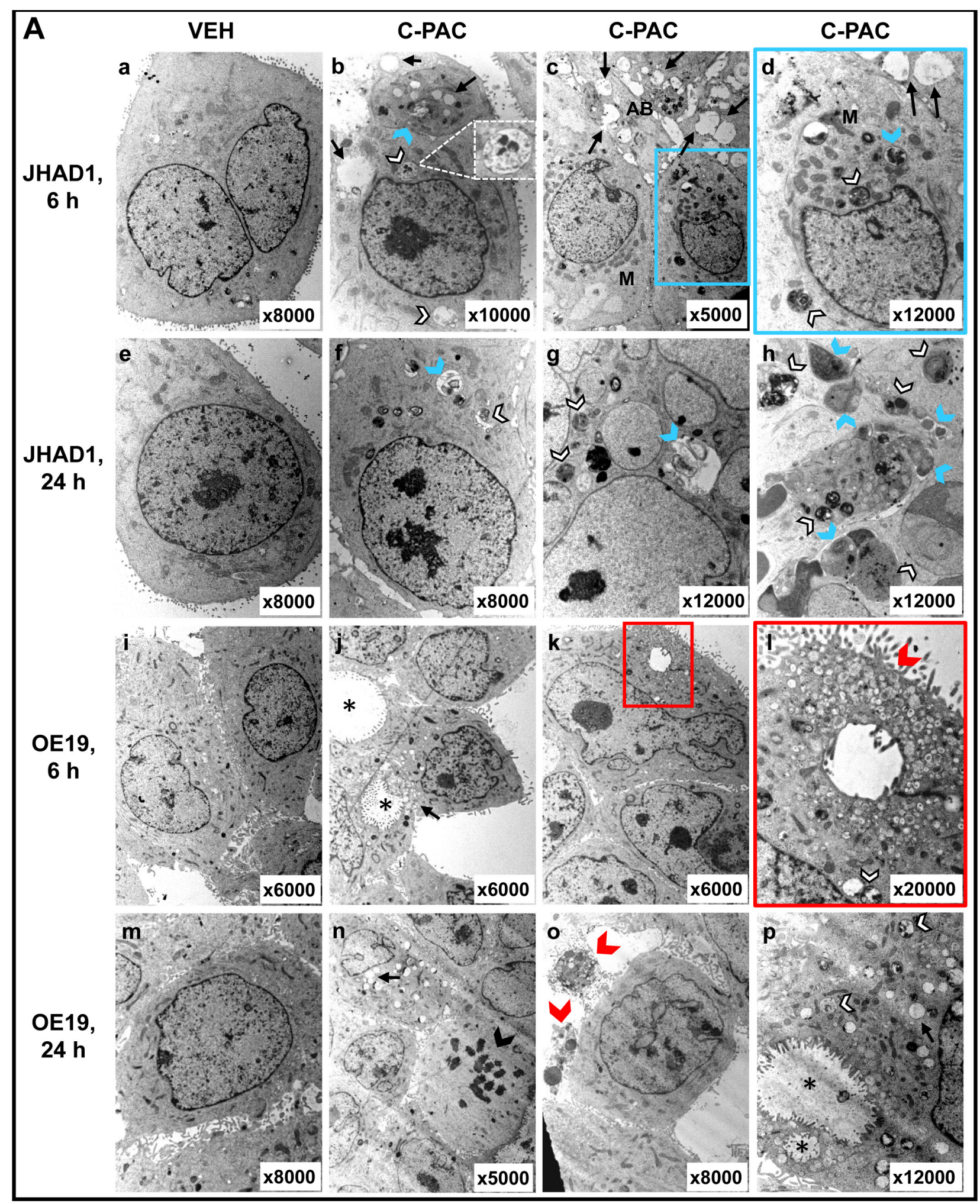



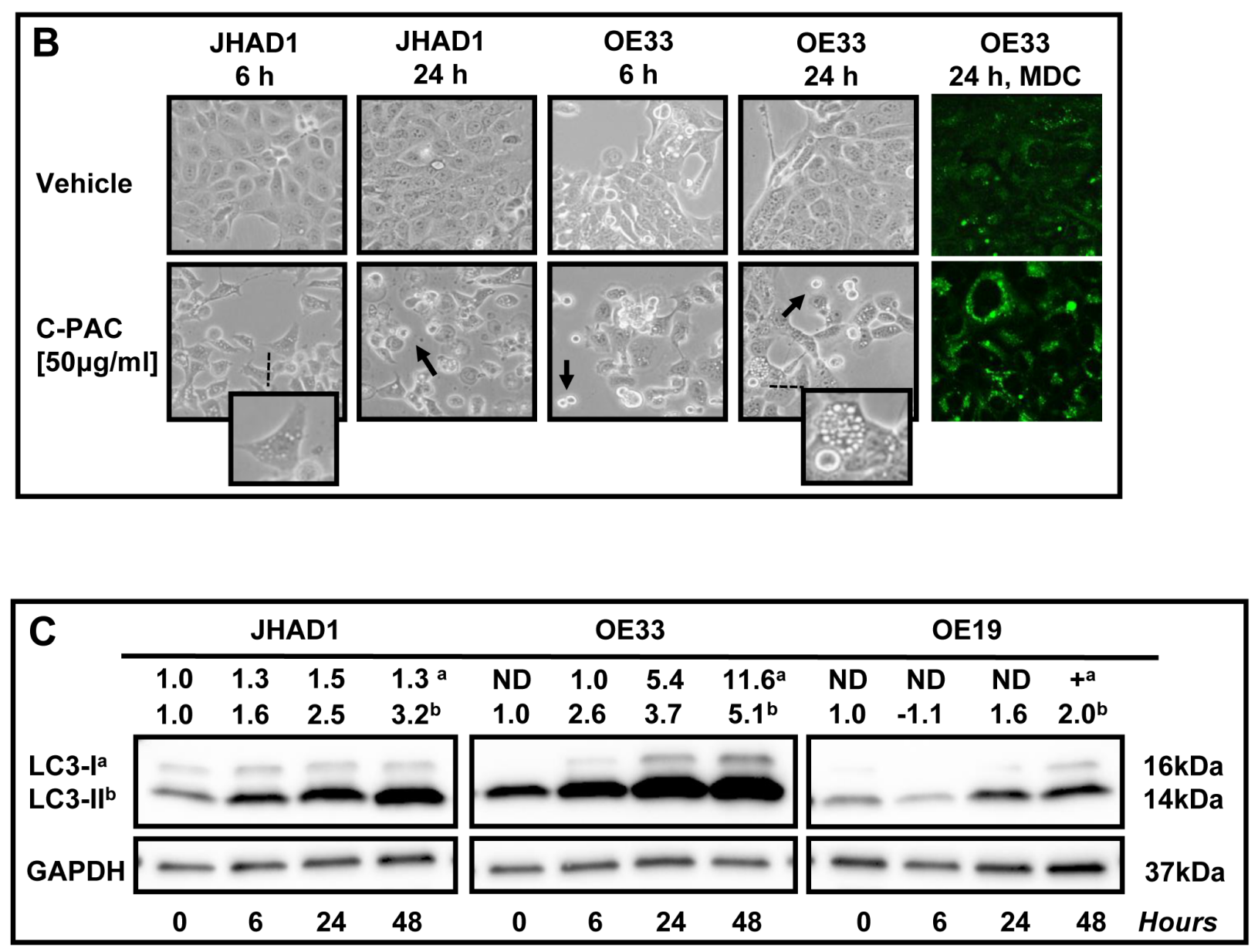

Figure 3: Effect of C-PAC on autophagy induction in EAC cells. A. Ultrastructural changes associated with C-PAC treatment of EAC Cells. Transmission electron micrographs were captured of JHAD1 and OE19 cells following 6 and 24 hours of treatment with C-PAC $[50 \mu \mathrm{g} / \mathrm{ml}]$ to evaluate autophagic vacuole formation. a) and e) show vehicle treated JHAD1 cells; whereas, i) and m) show vehicle treated OE19 cells at 6 and 24 hours, respectively. Vehicle treated cells are characterized by microvilli protruding from the cell surface, a round smoothly outlined normal appearing nuclei, normally distributed heterochromatin, well defined plasma membrane and well preserved cytoplasmic organelles. b), c), and d) show cytoplasmic vacuolization (black arrows), increased formation of single and double walled autophagic vesicles as shown as autophagosomes (blue arrowheads) and autolysomes (white arrowheads, black outline) as early as 6 hours post C-PAC treatment of JHAD1 cells. Increased autophagy continues 24 hours following C-PAC treatment as displayed in f), g), and h) with increased electron dense cargo supporting formation of degradative autophagic vacuoles. C-PAC treatment of OE19 cells induced cellular necrosis as illustrated in j) and $\mathrm{k}$ ) by moderate chromatin clumping and nuclear disintegration or karyolysis (asterisk), accompanied by loss of plasma membrane integrity and marked loss of cellular contents as in k), 1), and o) (extra-cytoplasmic cellular debris, red arrowhead). Cellular blebbing $(\mathrm{k}, \mathrm{n})$ and fragmentation of the nucleus (Karyorrhexis, black arrowhead) are evident. p) Autophagic vacuoles containing cellular debris indicate a low level of autophagy induction in OE19 cells. B. Representative photomicrographs (200X) of JHAD1 and OE33 EAC cells treated with C-PAC [50 $\mu \mathrm{g} / \mathrm{ml}]$ for 6 and 24 hours, black arrows indicate apoptotic cells. The enlarged inset illustrates morphological changes of cytoplasmic swelling and vacuolization consistent with autophagy induction (as also noted in Figure 1D). Monodansylcadaverine (MDC) staining and confocal microscopy were employed next to probe autophagic vacuoles in OE19, JHAD1 and OE33 cells following C-PAC treatment $[50 \mu \mathrm{g} / \mathrm{ml}]$ for 24 hours. C-PAC treatment of OE33 cells resulted in increased accumulation of punctate staining as illustrated in large MDC positive vesicles (far right, bottom panel). C. To further investigate C-PAC induced autophagy, JHAD1, OE33 and OE19 cells were treated with C-PAC [50 $\mu \mathrm{g} / \mathrm{ml}]$ or vehicle in triplicate and lysates collected at baseline and following 6, 24 and 48 hours of treatment; then, probed for LC3B, microtubule-associated protein 1 light chain 3 beta, an important early marker and effector of autophagy. Representative images are shown, expression values were normalized to the loading control GAPDH and a mean fold change from baseline or time of first detection calculated utilizing Quantity One software (Bio-Rad, Hercules, CA). Positive fold change values indicate increased expression and negative values reflect decreased expression. Figure $3 \mathrm{C}$ shows that $\mathrm{C}$-PAC strongly $(P<$ $0.05, t$-test) induces the autophagy-associated lipidated form of LC3-II in JHAD1 and OE33 cells at $24 \mathrm{~h}$ and 48 hours; conversely, C-PAC treatment of OE19 cells modestly increased the autophagic form of LC3 and non-lipidated LC3-I levels were not detected until 48 hours. 
C-PAC treatment of JHAD1 and OE33 cells. JHAD1 cells treated with C-PAC showed the formation of elongated spindle shaped cells and increased cytoplasmic extensions, early cytosolic vacuolization (enlarged inset), cytoplasmic swelling, yet intact nuclei in subpopulations of cells. The far right panel of Figure 3B shows a representative MDC stained image of OE33 cells treated with vehicle (top) and C-PAC [50 $\mu \mathrm{g} / \mathrm{ml}]$ (bottom). Fluorescent MDC staining shifted from a generalized weak and diffuse pattern in vehicle treated cells to a pattern of significant cell enlargement and markedly increased accumulation of intense punctate MDC positive vesicles 24 hours post C-PAC treatment [50 $\mu \mathrm{g} / \mathrm{ml}]$ consistent with autophagy induction. A similar pattern was noted in JHAD1 cells, but not OE19 cells (data not shown).

To further investigate C-PAC induced autophagy, JHAD1, OE33 and OE19 cells were treated with C-PAC $[50 \mu \mathrm{g} / \mathrm{ml}]$ or vehicle and lysates collected at baseline and following 6, 24 and 48 hours of treatment; then, probed for LC3, microtubule-associated protein 1 light chain 3 beta, an important early marker and effector of autophagy. LC3 is modified via an ubiquitylation-like system generating a soluble form, LC3-I, which in turn is modified during autophagy induction to a membrane-bound form, LC3II. Starting at 6 hours, C-PAC strongly induced the autophagy-associated lipidated form of LC3-II in JHAD1 and OE33 cells (Figure 3C $P<0.05, t$-test) with increased magnitude at 24 and 48 hours (2.5 to 5.1-fold) supporting early autophagosome formation. Conversely, C-PAC treated OE19 cells modestly increased the autophagic form of LC3 (1.6 to 2.0 fold, $P<0.05$ ) and non-lipidated LC3-I levels were not detected until 48 hours suggesting altered autophagy machinery and differing constitutive expression levels across EAC cell lines.

\section{Effect of C-PAC on cell-cycle, P53, PI3K/AKT/ mTOR, p38 MAPK and cell-death associated proteins in EAC cells}

JHAD1, OE33 and OE19 were treated with C-PAC [50 $\mu \mathrm{g} / \mathrm{ml}]$ or vehicle and lysates isolated at $0,6,24$ and 48 hours. As shown in Figure 4A-4E, EAC cell lines were assessed for temporal changes in the expression of proteins involved in cell cycle (Cyclin A1, Cyclin B1, P16, P21), P53 signaling (P53, P73, P-P53 at SER46 and SER15), kinase signaling (P-JNK, P-ERK, P-P38), PI3K/AKT/ mTOR (mTOR, P-mTOR, p70S6K, P-p70S6K, AKT, $\mathrm{P}^{-A K T^{\mathrm{Thr}} \text { 08 }}, \mathrm{P}^{-A K T^{\mathrm{Ser}} \text { 73 }}, \mathrm{P}-\mathrm{pTen}$ ) apoptosis (cleaved PARP, BCL-xL, BAK1, BAX, Cytochrome C, Caspases $3,4,7,8,9)$ and autophagy (LC3B). Expression values were normalized to the appropriate loading control and a foldchange from baseline or first detection calculated.

Considering C-PAC induced changes in cell cycle distribution we measured effects on levels of select cell cycle regulatory proteins (Figure 4A). Cyclin A1 regulates both the $\mathrm{G}_{1}-\mathrm{S}$ and $\mathrm{G}_{2}-\mathrm{M}$ checkpoints, whereas Cyclin B1 is a regulator of mitosis. Cyclin A1 levels were essentially unchanged in C-PAC treated JHAD1 cells; markedly reduced in OE33 cells (1.5-fold and 4.7fold at 24 and 48 hours); and in OE19 cells, levels were transiently decreased followed by a 1.4 -fold increase at 48 hours. Levels of cyclin B1 were increased in JHAD1 C-PAC treated cells (1.9-fold, 48 hours); whereas, levels declined to undetectable in OE33 cells following C-PAC treatment (24 and 48 hours). Cyclin B1 levels were not detected in OE19 cells at baseline or following treatment. C-PAC treatment increased expression levels of the tumor suppressor, P16 in a time-dependent manner in only OE33 cells ( 1.4 fold at 6 and 24 hours, 2.0 fold at 48 hours) which is promising considering its linkage to EAC progression. Levels of P16 were unchanged in OE19 cells and undetectable in JHAD1 cells where it is known to be deleted. Next, P21 was evaluated given its role in diverse cell cycle regulatory function at both $G_{1}$ and $G_{2}-M$ checkpoints. Although basal levels of P21 were low in all EAC cell lines, C-PAC treatment increased levels showing an early, but transient 4.0-fold level increase in JHAD1 cells and increased levels in OE19 cells at 6 and 24 hours. Whereas, OE33 cells showed the highest magnitude and sustained increase in P21, changing from non-detectable levels at baseline to 1.7- and 2.3-fold increased levels at 24 and 48 hours, respectively. Also linked with p21 and cell cycle regulation is the critical tumor suppressor protein P53 which is inactivated early, frequently and linked to poor prognosis for EAC $[33,34]$ and is now known to be mutated in all three EAC cell lines evaluated [35]. JHAD1 cells expressed P53 in all forms and C-PAC induced a 2 -fold increase in pro-apoptotic P-p53 $3^{\text {ser46 }}$ and an increase in P-p53 $3^{\text {ser15 }}$ at 6 hours; whereas, in OE19 cells C-PAC induced strong expression of only P-p53 $3^{\text {ser15 }}$ which is linked to DNA damage induced cell death. JHAD1 cells reportedly have a somatic mutation in exon 8 resulting in a non-synonymous Gly 266 Glu alteration [36]. Still, in JHAD1 cells, C-PAC induced cell death may be partially p53-mediated as the p53 target BAX is also up-regulated (1.4 fold, 48 hours). OE19 cells are reported to have partially functional p53, despite showing a total lack of P53 expression and very low P-P53 $3^{\text {ser46 }}$ expression. OE33 cells have a p53 mutation in exon 5, resulting in non-functional nuclear protein accumulation and weak expression of P-P53 ${ }^{\text {ser46 }}$. The $\mathrm{p} 53$ homolog p73, known to mediate apoptosis and autophagy via the mTOR pathway [36, 38] was also evaluated. C-PAC treatment resulted in a consistent temporal increase (6-48 hours) in P73 expression levels in OE19 and JHAD1 cells, but P73 levels in C-PAC treated OE33 cells were unchanged followed by a reduction at 48 hours.

Mitogen-activated protein kinases (MAPKs) are a family of serine-threonine kinases that constitute a dominant signaling pathway in esophageal adenocarcinoma progression and have an essential role 

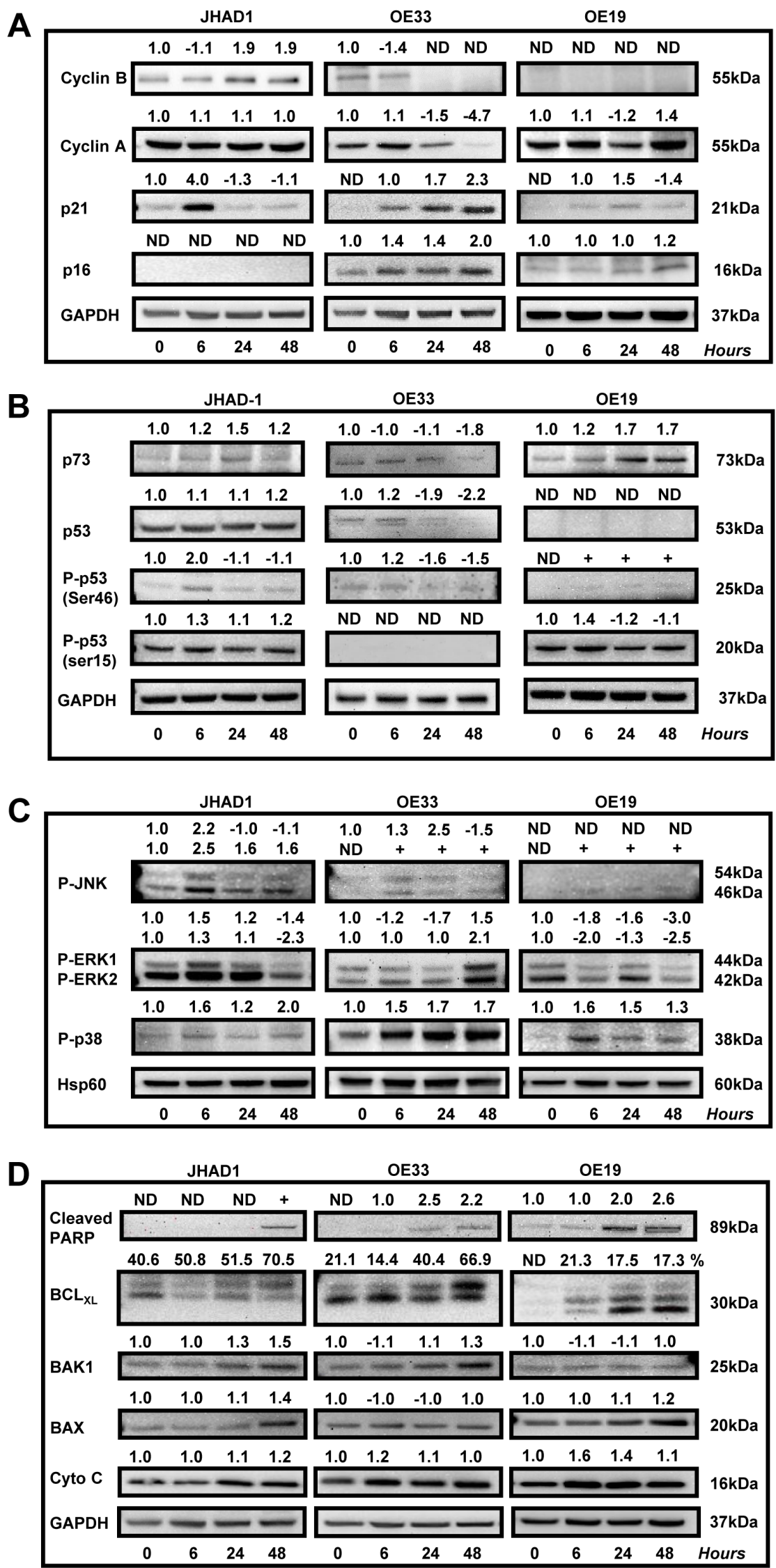


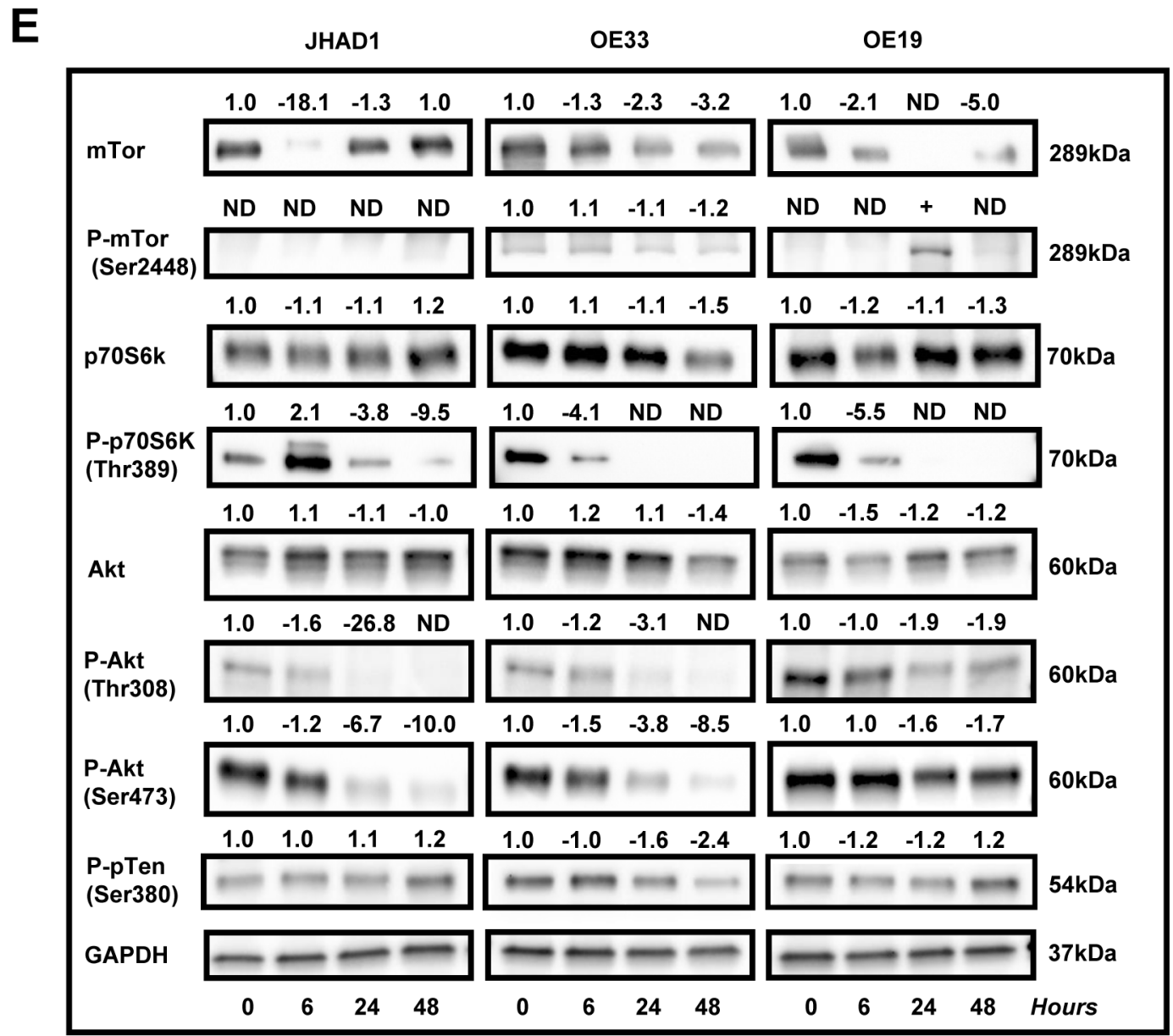

Figure 4: Effect of C-PAC on cell-cycle, P53, PI3K/AKT/mTOR, p38/MAPK and cell-death associated proteins in EAC cell lines. JHAD1, OE33 and OE19 EAC cells were treated with C-PAC [50 $\mu \mathrm{g} / \mathrm{ml}]$ or vehicle and lysates isolated at pretreatment or baseline and at 6,24 and 48 hours following treatment. Immunoblot was performed using commercially available antibodies to proteins of interest. Expression values were normalized to the appropriate loading control, GAPDH or HSP60, and a fold change from baseline or first detection calculated based on two independent experiments. Positive fold change values indicate increased expression and negative values reflect decreased expression, except for BCL-xL. The top or deamidated BCL-xL band was quantified as a percentage of the total species to differentiate between the molecules pro- and anti-apoptotic characteristics. Effects of C-PAC treatment on the expression of a panel of A. cell-cycle regulatory molecules; B. P53 family members; C. MAPK signaling molecules; D. Pro- and anti-apoptotic markers; and E. PI3K/AKT/mTOR signaling molecules.

in signal transduction, cellular growth, proliferation, migration and death [39]. MAPKs are comprised of extracellular signal regulated kinases (ERKs), c-Jun $N$-terminal kinases (JNKs) and p38 MAPKs, each of which we evaluated in EAC cells following C-PAC treatment (Figure 4C). JNK phosphorylation was generally increased in EAC cells by C-PAC treatment; however, the level, temporality and magnitude differed across cell lines. More striking expression changes were noted in both P-ERK1 (44 kD) and P-ERK2 (42 kD). C-PAC treated JHAD1 cells showed increased P-ERK1/2 levels at $6 \mathrm{~h}$ (1.5/1.3-fold, respectively). In contrast, P-ERK1/2 declined in a temporal manner in treated OE19 cells starting at 6 hours, with greatest effects at 48 hours. In OE33 cells, C-PAC treatment decreased levels of P-ERK1 at 6 and 24 hours (1.2 and 1.7-fold) followed by 2.1 -fold increased P-ERK2 levels at 48 hours. C-PAC increased levels of P-p38, a marker generally thought to have a tumor suppressive role. JHAD1 cells showed a biphasic change in P-p38 in response to treatment (1.6, 1.2-and 2.0fold increased levels at 6, 24 and 48 hours, respectively). P-p38 levels were strongly expressed in OE33 cells and increased in a time-dependent manner from 1.5 -fold at 6 hours to 1.7 -fold at 48 hours. Treated OE19 cells showed increased (1.6-fold) P-p38 at 6 hours, followed by gradual reductions through 48 hours. Our data support differential activation of MAPK molecules by C-PAC temporally and in a cell-line specific manner.

Considering C-PACs ability to induce apoptosis, autophagy and necrosis, a host of key cell death signaling molecules were evaluated. PARP cleavage is considered a hallmark of apoptosis induction, but is also implicated 
in DNA repair and DNA-damage induced autophagy [40-42]. All EAC cell lines showed a time-dependent increase in PARP cleavage after C-PAC treatment, with the strongest and earliest induction noted in OE19 cells (Figure 4D). However, C-PAC treatment failed to activate effector caspase 7 in EAC cells (Supplemental Figure $2 \mathrm{~S}$ ) and caspase 3 cleavage was weak, only detected with extended exposure times. In addition, C-PAC had little effect on initiator caspases 8 or 9 or caspase 4 , involved in inflammatory cytokine processing. C-PAC induced
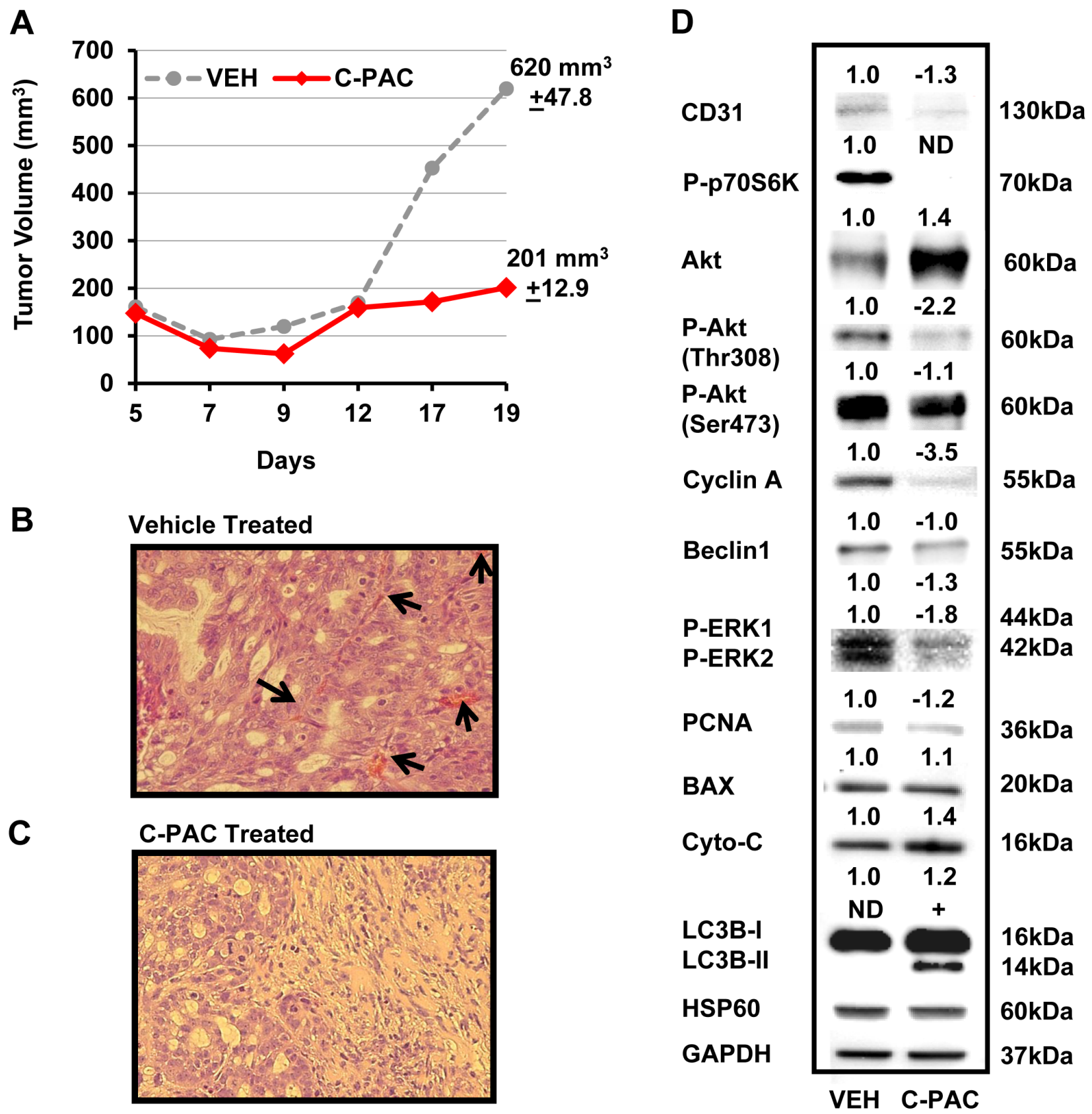

Figure 5: Effect of C-PAC treatment on OE19 xenografts in athymic NU/NU mice. Mice were implanted s.c. with $1.25 \times 10^{6}$ OE19 cells in each flank. Tumors grew for 5 days reaching a mean tumor volume of $150 \mathrm{~mm}^{3}$ prior to mice being randomized into vehicle or C-PAC treatment groups. C-PAC was delivered by oral gavage at a concentration of $250 \mu \mathrm{g} / \mathrm{mouse}, 6$ days a week. Increasing tumor size in the vehicle treated groups required termination of the experiment on day 19. Data are shown as mean percentages $+\mathrm{SEM}$. ${ }^{*} P<0.05$ indicates a significant difference between C-PAC and vehicle treated mice, two-tailed Students $t$-test. A. C-PAC administration significantly inhibited mean tumor volume by $67.5 \%$ compared to tumors in vehicle treated mice. B. Vehicle treated tumors had greater cellular pleomorphism, inflammation (lower left) and markedly increased blood vessel formation as evidenced by areas of bright eosinophilia (black arrows) C. C-PAC treated tumors displayed areas of relatively normal epithelium as well as glandular precursor lesions, similar to Barrett's esophagus. D. Protein lysates isolated from C-PAC treated OE19 xenografts showed alterations in AKT/mTOR/MAPK signaling and specific markers linked to cell cycle progression, apoptosis, and autophagy compared to vehicle treated xenografts. 
expression of pro-apoptotic BCL2 members, BAX and BAK in JHAD1 cells ( $48 \mathrm{~h}$ ) and increased BAK in OE33 cells (48 h). Additionally, the phosphorylated form of BCL2, which acts to suppress the anti-apoptotic effects of BCL2, was modestly elevated only in OE19 cells at 24 and $48 \mathrm{~h}$ (data not shown), but not detectable in JHAD1 or OE33 cells. C-PAC treatment increased levels of the pro-apoptotic deamidated form of BCL-xL [43, 44], in a time-dependent manner as indicated by the percentage comprising the upper band of BCL-xL (Figure 4D), in both JHAD1 (40.6-70.5\%) and OE33 (14.4-66.9\%) cells. In contrast, OE19 cells showed increased expression of deamidated BCL-xL, but the magnitude was much lower (17.3-21.3\%) supporting greater resistance.

As shown in Figure 4E, C-PAC treatment strongly inactivated $\mathrm{PI} 3 \mathrm{~K} / \mathrm{AKT} / \mathrm{mTOR}$ signaling networks as supported by total loss or significant reduction of P-p70S6k, P-Akt ${ }^{\text {Thr308 }}$ and P-Akt ${ }^{\text {Ser473 }}$ expression in all EAC cell lines 24 and 48 hours post C-PAC treatment. mTOR levels also decreased following C-PAC treatment. Collectively, the results support C-PAC inhibition of mTORC1 and mTORC2 signaling. P-pTEN was evaluated given its role in the regulation of $\mathrm{PI} 3 \mathrm{~K} / \mathrm{AKT}$ signaling and autophagy induction. C-PAC markedly reduced levels of P-pTEN at 24 and 48 hours (1.6 and 2.4-fold, respectively) in OE33 cells; resulted in minor reductions in OE19 cells, but had little impact in JHAD1 cells indicating a cell line specific effect between pTEN dephosphorylation and AKT inactivation.

\section{C-PAC inhibited growth of OE19 tumor xenografts by modulation of cell cycle, PI3K/ AKT/mTOR and MAPK signaling pathways}

On the basis of our positive in vitro results supporting C-PAC has cancer inhibitory potential in EAC cells; we next evaluated the in vivo tumor inhibitory potential of C-PAC utilizing OE19 xenografts in an athymic NU/NU mouse model. Unlike OE33 and JHAD1 cells, OE19 cells readily formed xenograft tumors reaching $150 \mathrm{~mm}^{3} 5$ days post-injection of $1.25 \mathrm{E} 6 \mathrm{OE} 19$ cells per flank. On day 5 , mice were randomized to receive vehicle or C-PAC [250 $\mu \mathrm{g} /$ day] via gavage $6 \mathrm{x}$ weekly. Figure 5A-5D summarizes C-PACs effects on OE19 tumor growth, tumor morphology and alterations in the expression levels of cell cycle, proliferative, apoptotic, and AKT/mTOR/MAPK signaling proteins. C-PAC treatment did not alter body weight or food consumption (data not shown) in treated mice. Orally delivered C-PAC [250 $\mu \mathrm{g} /$ day] resulted in a significant, $67.6 \%$, decrease in xenograft tumor volume. Figure 5B, illustrates that vehicle treated tumors had increased blood vessel formation as evidenced by areas of bright eosinophilia (black arrows). Whereas, C-PAC treated xenografts $(\mathrm{C})$ displayed large areas of relatively normal epithelium mixed with focal glandular

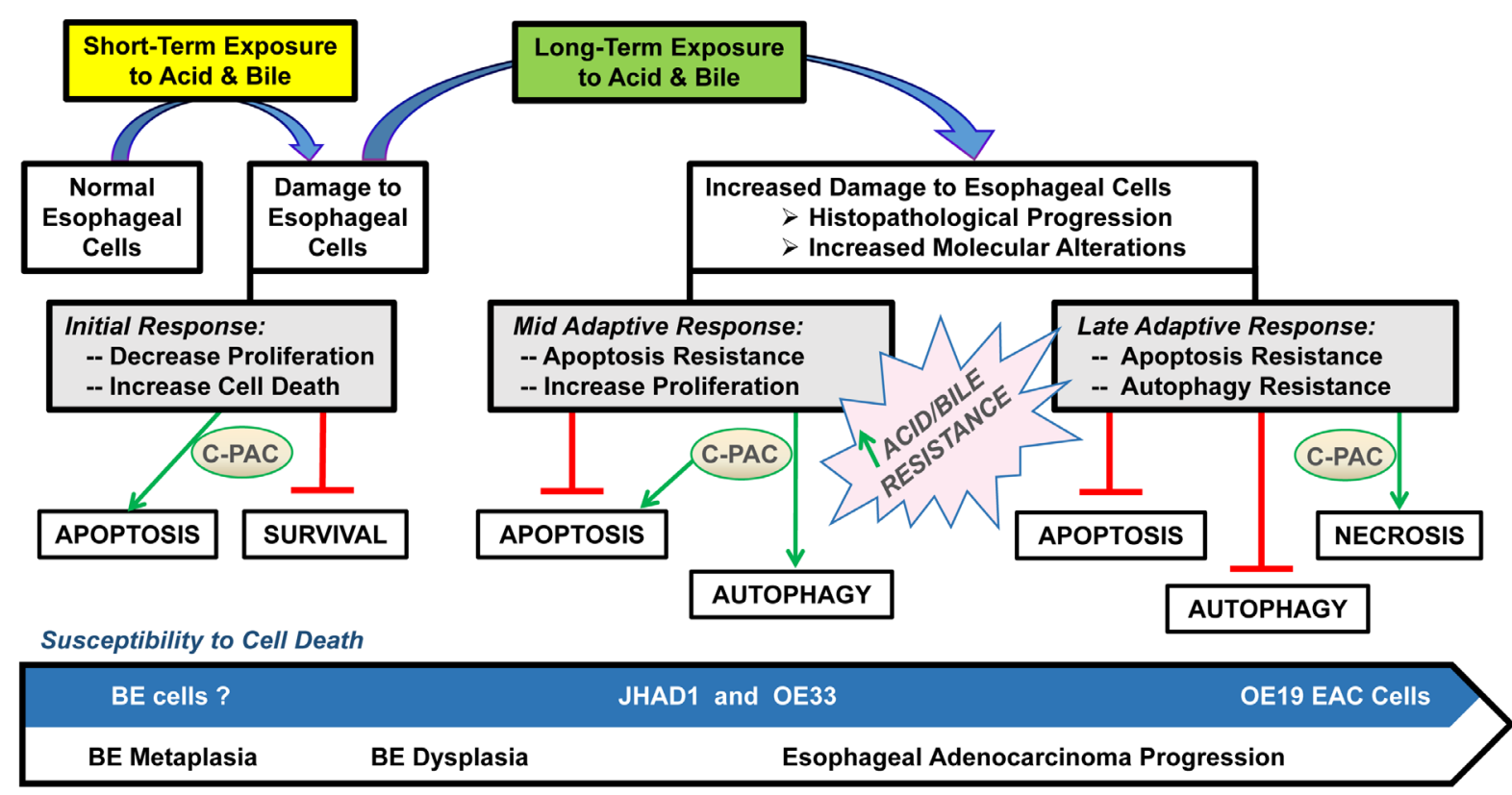

Figure 6: Proposed model for C-PAC induced cell death in EAC cell lines. Results support C-PAC induces cell death by different mechanisms in EAC cell lines based on sensitivity to an acidified bile mixture. Exposing acid sensitive JHAD1 and OE33 EAC cells to an acidified bile cocktail $(5 \mathrm{~min}, \mathrm{pH}=4.0)$ resulted in rapid cell death via early apoptosis; however, exposure of inherently acid resistant OE19 EAC cells does not result in significant cell death. C-PAC treatment of JHAD1 and OE33 cells results in cell death via low levels of apoptosis and significant autophagy; whereas C-PAC treated OE19 cells die largely by cellular necrosis and exhibit low levels of autophagy and apoptosis. Similarly, when JHAD1 cells are pushed to become resistant to the acidified bile cocktail (4-6 repeat exposures) the cells die via necrosis supporting that mode of cell death induction is linked to sensitivity to an acidified bile cocktail. 
precursor lesions. Lysates isolated from C-PAC treated OE19 xenografts (D) showed decreased expression in the proliferative marker PCNA and to a greater extent cyclin A; cyclin B1 was not detected (data not shown). $\mathrm{C}$-PAC treatment resulted in increased levels of proapoptotic cytochrome C (1.4-fold) and reduced P-ERK levels in C-PAC treated tumors, in line with decreased levels detected in C-PAC treated OE19 cells. C-PAC treatment also induced dephosphorylation of p70S6K, $\mathrm{AKT}^{\mathrm{Thr} 308}$, and reduced $\mathrm{P}-\mathrm{AKT}^{\mathrm{Ser} 473}$ paralleling in vitro results. Lastly, C-PAC induced expression of autophagy associated LC3B-II in OE19 xenografts, but not Beclin-1 levels. Neither P-pTen nor activated caspases (3, 7 or 9) were detected in C-PAC treated xenograft lysates.

\section{DISCUSSION}

Esophageal adenocarcinoma represents a significant health problem characterized by rapidly rising incidence, substantial morbidity and high mortality. Barrett's esophagus is the only recognized precursor lesion and although BE patients are successfully treated to relieve symptoms associated with acid reflux, none of the current therapies have proven inhibitory against EAC development. Considering the majority of $\mathrm{BE}$ patients are relatively healthy and do not progress to EAC [45] identification of non-toxic cancer inhibitory agents, acceptable for long-term administration, are needed. A number of bioactive constituents derived from plant or food-based sources have favorable toxicity profiles and hold promise as cancer inhibitors. Cranberry constituents have been shown to have strong anti-proliferative and apoptosis inducing capacity in a number of cancer cell lines and in a limited number of in vivo models [1525]; however, pathways of inhibition are incompletely understood. Thus, the current study evaluated C-PAC induced EAC cell death mechanisms in vitro and in vivo to improve our understanding of targetable molecular pathways and the context in which EAC inhibition is permissive.

Results of the current study demonstrated that C-PAC has potent EAC cell death inducing capacity and strongly inhibits growth of EAC tumor xenografts. The research results presented appear to be the first to demonstrate C-PAC induced autophagy resulting in cancer cell death and the first to report in vivo efficacy of orally delivered C-PAC against EAC. Oral administration of C-PAC resulted in significantly reduced (68\%) OE19 xenograft volume linked to markedly increased formation of autophagic LC3B-II and inactivation of PI3K/AKT/ mTOR signaling as evidenced by dephosphorylation of p70S6K, AKT ${ }^{\text {Ser473 }}$ and to a lesser extent $\mathrm{AKT}^{\mathrm{Thr} 308}$. Interestingly, autophagy induction in vitro and in vivo appeared to be Beclin-1 independent; also, reported to occur with treatment of resveratrol [46] and cisunsaturated fatty acids [47]. Other effects noted in lysates from C-PAC treated mice include increased levels of pro-death BAX and Cytochrome $\mathrm{C}$, reduced Cyclin A and PCNA, as well as reduced P-ERK1/2 supporting additional effects on MAPK signaling networks. Fitzgerald and colleagues identified the MAPK pathway to be highly induced (42.7\%) following receptor tyrosine kinase activation (RTK) in esophago-gastric tumors [48]. Importantly, bile and/or acid exposure, well-documented risk factors for EAC, are linked to aberrant MAPK and $\mathrm{PI} 3 \mathrm{~K} / \mathrm{AKT} / \mathrm{mTOR}$ signaling [26-32, 48]. Also downstream of RTK activation is the PI3K/AKT/mTOR pathway regulating diverse cellular functions involved in EAC cancer progression including advanced tumor stage, poor prognosis and therapeutic resistance [49-53]. Hence, results are promising in that C-PAC mitigates aberrant $\mathrm{PI} 3 \mathrm{~K} / \mathrm{AKT} / \mathrm{mTOR}$ and MAPK signaling cascades in vivo and in vitro. Moreover, in vitro findings support that the mode of C-PAC induced cell death varies based on acid resistance of the EAC cells. C-PAC induced cell death via low levels of mainly caspase independent apoptosis and significant autophagy in acid-sensitive JHAD1 and OE33 EAC cells, but mainly through cellular necrosis in OE19 cells which exhibited greater constitutive resistance to acidified bile salt exposure, as well as resistance to apoptosis and autophagy induction, as summarized in Figure 6. The role of autophagy in EAC and BE is a poorly understood and understudied area to date. Dvorak and colleagues recently reported a significant decrease in expression of Beclin-1, a key autophagy regulator, in dysplastic BE and EAC cases compared to non-dysplastic $\mathrm{BE}$ tissues and normal squamous epithelium [54]. Interestingly, acute bile acid exposure increases Beclin-1 levels inducing autophagy; whereas, chronic or longterm bile acid exposure leads to a reduction in Beclin-1 expression and inhibition of autophagy [54]. Our results lend further support to autophagy induction as a pro-death mechanism in EAC, particularly in apoptosis resistant cells. Beclin-1 expression is linked to improved survival in patients with squamous cell cancer of the esophagus [55], but additional autophagy research is warranted in the context of EAC disease progression and prognosis given clinical interest in both autophagy inhibitors and inducers as therapeutic agents.

Cell line specific responses following C-PAC treatment were noted for select cell cycle and cell death associated markers; yet, common biological responses included $\mathrm{G}_{2}-\mathrm{M}$ cell cycle arrest. The strongest effects of C-PAC induced $\mathrm{G}_{2}-\mathrm{M}$ arrest were noted in OE33 cells, followed by OE19 and significant, but modest effects in JHAD1 cells. Cyclin A1 regulates both the $\mathrm{G}_{1}-\mathrm{S}$ and $\mathrm{G}_{2}-\mathrm{M}$ checkpoints, correlates with degree of dysplasia in $\mathrm{BE}$ patients and is linked to cancer invasiveness [52, 53]. Cyclin A1 levels were essentially unchanged in C-PAC treated JHAD1 cells, markedly reduced in OE33 cells (4.7-fold), transiently decreased in OE19 cells (1.2fold), and markedly reduced (3.5-fold) in C-PAC treated 
xenografts. Cyclin B1, charged with transitioning cells from $\mathrm{G}_{2}$ to $\mathrm{M}$, was not detected in OE19 cells; whereas, levels decreased 24 hours post-treatment in OE33 cells to below detection limits as is commonly reported with $\mathrm{G}_{2}-\mathrm{M}$ arrest and more specifically late $\mathrm{G}_{2}$ arrest. In contrast, C-PAC treated JHAD1 cells displayed increased Cyclin B1 levels (1.9-fold) suggesting M-phase arrest and potentially mitotic catastrophe resulting from DNA damage. DNA damage induced MAPK activation also contributes to p21 induction and cell cycle arrest. P21 is known to be involved in diverse cell cycle regulatory functions at both $\mathrm{G}_{1}$ and $\mathrm{G}_{2}-\mathrm{M}$ checkpoints. Interestingly, OE33 cells showed the highest magnitude and sustained increase in P21, changing from non-detectable at baseline to 2.3 -fold increased levels at 48 hours. The latter finding is potentially linked to the fact that $\mathrm{p} 21$ levels peak during $\mathrm{G}_{2}$ and that C-PAC induced the highest magnitude of $\mathrm{G}_{2}-\mathrm{M}$ arrest in OE33 cells.

In terms of cell death associated molecules, C-PAC treated EAC cells responded with increased cleaved PARP and cytochrome $\mathrm{C}$ levels, but effects were generally caspase independent, with only low level induction of activated caspase 3 (Supplemental Figure 2S). Caspaseindependent PARP cleavage can lead to apoptotic or necrotic cell death and our data suggests a role for autophagy induction as well. A novel unexpected finding was that C-PAC induced deamidation of BCL-xL, a prodeath form of the important pro-survival BCL-2 family member protein and one whose functional consequences are still being unraveled $[43,44,56]$. However, recent research suggests factors decreasing BCL-xLdeamidation may increase tumor cell viability and increase resistance to cancer treatment [56]. In brief, Weintraub and colleagues revealed that DNA damaging agents induce BCL-xL deamidation of two asparagines by disrupting the capacity of BCL-xL to inhibit the proapoptotic activity of $\mathrm{BH} 3$ domain-only proteins; in turn, increasing apoptosis susceptibility [42]. Results herein suggest the first time that BCL-xL deamidation may also play a role in autophagy induction in apoptotic resistant EAC cells.

Our data provide novel insight into mechanisms of C-PAC induced cell death in vitro and in vivo providing the first evidence that C-PAC activated autophagy serves as an alternative cell death pathway in apoptotic and acid resistant EAC cancer cells; yet, C-PAC targeted necrosis in apoptosis and autophagy resistant cells. C-PACs pro-death effects were accompanied by inactivation of $\mathrm{PI} 3 \mathrm{~K} / \mathrm{AKT} / \mathrm{mTOR}$ signaling, modulation of MAPKs and a $\mathrm{G}_{2}-\mathrm{M}$ cell cycle arrest. Still, additional research is warranted to assess the effects of C-PAC on mitophagy and chaperone-mediated autophagy as well as ROS generation and DNA damage. The current study results lay the foundation and direction for future research utilizing genetic and pharmacologic approaches to further improve our understanding of C-PACs potential to target EAC or Barrett's esophagus. Additional research is ongoing to assess the effects of C-PAC utilizing normal esophageal cells and a panel of premalignant BE cell lines, as well as a rat model in which reflux-inducing surgery results in EAC. Future in vivo research should also consider evaluations of primary esophageal xenografts which have the advantage of preserving cancer stem cell populations, stromal components and greater functional characteristics of the primary cancer [57] and in turn may offer improved personalized preventive or therapeutic approaches.

\section{MATERIALS AND METHODS}

\section{Cranberry extract isolation, purification and dose determination}

Cranberry fruit (Vaccinium macrocarpon Ait.) was collected at the Marucci Center for Blueberry and Cranberry Research, Chatsworth, NJ. Purified C-PAC extract was isolated from cranberries of the 'Early Black' cultivar utilizing solid-phase chromatography according to well established methodology [9-12]. In brief, the fruit was homogenized in $70 \%$ aqueous acetone, filtered and the pulp discarded. Collected cranberry-derived proanthocyanidins were concentrated under reduced pressure and purified extract isolated using bioassaydirected fractionation. The absence of absorption at $360 \mathrm{~nm}$ and $450 \mathrm{~nm}$ confirm all but proanthocyanidins are removed. Additional methods including ${ }^{13} \mathrm{C}$ NMR, electrospray mass spectrometry, matrix-assisted laser desorption/ionization time-of-flight mass spectrometry, and acid catalyzed degradation with phloroglucinol were utilized to verify the presence of A-type linkages as well as to determine the concentration of proanthocyanidins in the purified extract. C-PAC is comprised of five main proanthocyanidins as previously characterized by Dr. Howell and colleagues [11]. The proanthocyanidin molecules largely consist of epicatechin units with degrees of polymerization of 4 or 5 , as well as epigallocatechin and catechin. C-PAC contains three types of linkages, two common B-type linkages $(C 4 \rightarrow C 6$ and $C 4 \rightarrow C 8)$ and at least one unique A-type ether linkage $(C 2 \rightarrow O \rightarrow C 7)$ found only in cranberry, chokeberry, plums and avocado [14, 15]. Purified C-PAC was freeze-dried and stored at $-80^{\circ} \mathrm{C}$. $\mathrm{C}-\mathrm{PAC}$ concentrations chosen for study were informed by our earlier research which determined the LD50 to be in the 50 to $100 \mu \mathrm{g} / \mathrm{ml}$ range in various cancer cell lines [1618]. Consideration was also given to earlier evaluations by Howell and colleagues showing $50 \mu \mathrm{g} / \mathrm{ml}$ of C-PAC inhibits adhesion of p-fimbriated uropathogenic E. coli bacteria in vitro and that $36 \mathrm{mg} /$ day of C-PAC delivered in 10 ounces of juice inhibits bacterial adhesion in the urinary tract wall of humans [9-13]. Importantly, the concentrations of C-PAC under evaluation in this series of preclinical investigations are readily achievable in humans 
and are already under evaluation for oral and urinary tract health benefits.

\section{Cell culture}

Authenticated human EAC cell lines utilized in this series of experiments [32] included JH-ESOAd1, referred to as JHAD1, isolated from a distal EAC, stage III, N0 in 1997 (Johns Hopkins University, Baltimore, MD); OE33 cells isolated in 1993 from a distal EAC, stage II, N0, (ECACC, Wiltshire, UK); and OE19 cells isolated in 1993 from an adenocarcinoma at the gastro-esophageal junction, stage III, N1 (ECACC, Wiltshire, UK). Cells were grown in RPMI 1640 complete medium containing L-glutamine (2.0 $\mathrm{mM})$, penicillin $\left(10^{4}\right.$ units $\left./ \mathrm{mL}\right)$, streptomycin $\left(10^{4}\right.$ $\mu \mathrm{g} / \mathrm{mL})$, sodium pyruvate $(1 \mathrm{mM})$, and $5-10 \%$ fetal bovine serum depending on the experiment. Cells were maintained as monolayers at $37{ }^{\circ} \mathrm{C}$ with $95 \%$ air and $5 \%$ $\mathrm{CO}_{2}$ for all studies.

\section{Determination of apoptosis, phase of cell cycle and BrdU levels by flow cytometry}

OE19, JHAD1 and OE33 cells were plated in T25 flasks at $1.5 \mathrm{E} 6,1.0 \mathrm{E} 6$ and $1.0 \mathrm{E} 6$ cells, respectively and incubated for 24-30 hours prior to treatment with C-PAC [50 or $100 \mu \mathrm{g} / \mathrm{ml}]$ or vehicle $[<0.001 \%$ ETOH] in phenol red free RPMI complete medium with 5\% FBS. Each evaluation was performed in triplicate per experimental time-point. Cell cycle distribution was assessed at 24 and 48 hours utilizing propidium iodide (PI) detection (BD Sciences, Palo Alto, CA) as previously described [1618]. Briefly, harvested cells were fixed in ice cold $70 \%$ EtOH, washed in PBS and stained with PI. A minimum of 20,000 cells were analyzed per treatment utilizing a FACSCalibur flow cytometer. ModFit LT software (Verity, Topsham, ME) was used to determine the percentage of cells in each phase of the cell cycle $\left(\mathrm{G} 0-\mathrm{G}_{1}, \mathrm{~S}, \mathrm{G}_{2}-\mathrm{M}\right)$. Concurrent BrdU $[10 \mu \mathrm{M}, 1 \mathrm{~h}$ incubation] and PI staining was conducted to improve our understanding of the S-phase distribution beyond that provided by PI-based analysis alone. BrdU distribution and intensity of staining was detected by FACSCalibur analyzing a minimum of 10,000 cells; whereas, Annexin V-FITC staining methods were employed to detect apoptotic and necrotic events counting a minimum of 10,000 cells with Flowjo software employed for analysis.

\section{Protein isolation and Western blot analysis}

JHAD1, OE33 and OE19 EAC cells were plated in T75 flasks at 1.5E6, 1.5E6 and 3E6 cells, respectively. Cells adhered for 24-30 hours, were treated with C-PAC $[50 \mu \mathrm{g} / \mathrm{mL}]$ or vehicle and harvested at $0,6,24$ and 48 hours post-treatment. Cell lysates were prepared using Cell Signaling lysis buffer (Cell Signaling Technology, Inc., Beverly, MA.). Protein was quantified using the Quick Start Bradford protein assay and equivalent protein amounts loaded into precast NuPage Novex Bis-Tris 10\% gels (Life Technologies, Carlsbad, CA.) and miniprotean TGX gels (4-20\%, 7.5\%, 10\% and 12\%; Bio-Rad). Immunoblotting was performed in duplicate or triplicate using commercially available antibodies from Santa Cruz Biotechnology (CD31, Cytochrome C, GAPDH, P16, P21, PCNA) and Cell Signaling (AKT, BAK1, BAX, BCL-xL, Beclin-1, Caspases 3/4/7/8/9, LC3B, Cyclin A1, Cyclin B1, PARP, P-AKT Thr308, P-AKT ${ }^{\text {Ser47 }}$, P-BCL-2 ${ }^{\text {Ser70 }}$, P-ERK, P-JNK, P-pTEN, P-P38, P-p70S6K, P-mTOR, p70S6K, all P53 family member antibodies and P73) to proteins of interest. Expression values normalized to loading controls were determined by chemiluminescent immunodetection with fold-change from baseline or first appearance reported.

\section{Acidified bile challenge and development of acid/ bile resistant cells}

EAC cells were treated with a $0.2 \mathrm{mM}$ acidified bile cocktail $(\mathrm{pH}=4.0)$ comprised of equal amounts taurocholic, glycocholic, glycodeoxycholic, glycochenodeoycholic and deoxycholic acids (Sigma-Aldrich) mimicking human refluxant [27]. Cells received either a single 5 minute pulsatile treatment with an acidified bile cocktail or a single treatment, followed by multiple additional exposures of 7.5 minutes every other day to simulate repeated reflux episodes. Each cell line was evaluated in terms of constitutive acid sensitivity, capacity to develop acid resistance and whether resistance impacted mode of C-PAC induced cell death.

\section{Transmission electron microscopy}

OE19 and JHAD1 cells were plated (2.5E4 and 1.2E4, respectively) in LabTek 4 well permanox chamber slides with RPMI complete medium and adhered for 30 hours prior to C-PAC [50 $\mu \mathrm{g} / \mathrm{ml}]$ treatment. Cells were harvested at 6 and 24 hours post-treatment and fixed overnight in $2 \%$ glutaraldehyde in $0.1 \mathrm{M}$ phosphate buffer, pH 7.4 containing $0.1 \mathrm{M}$ sucrose, followed by dehydration in a graded series of acetone, infiltration with resin, embedding, and preparation of $80 \mathrm{~nm}$ sections and staining. Sections were examined and transmission electron images captured to assess the ultrastructural features and the formation of autophagic vacuoles. 


\section{Monodansylcadaverine staining of autophagic vacuoles}

EAC cells were plated in four quadrant CELLview culture dishes (VWR, Radnor, PA.) with RPMI complete medium, allowed to adhere for 30 hours and then treated with C-PAC [50 $\mu \mathrm{g} / \mathrm{ml}]$ for 24 hours. Growth medium was removed and cells were stained with Monodansylcadaverine (MDC) (Sigma-Aldrich \#30432) for $30 \mathrm{~min}$ at $37^{\circ} \mathrm{C}$ to label acidic autophagic vacuoles which are part of the lysosomal compartment. Confocal microscopy was utilized to visualize the MDC fluorescence $(335 / 525 \mathrm{~nm}$, excitation/emission).

\section{Xenograft EAC tumor model}

All experimental procedures were conducted in accordance with a protocol approved by the Institutional Laboratory Animal Care and Use Committee of the University of Miami. Twelve 5-6 week old male NU/ NU athymic mice were purchased from Charles Rivers Laboratories, Wilmington, MA. Mice were fed irradiated synthetic AIN93G diet and provided water ad libitum. OE19 cells were suspended in RPMI medium and matrigel and subcutaneously implanted at a concentration of $1.25 \mathrm{E} 6$ cells in each flank; cells grew for 5 days reaching a mean tumor volume of $150 \mathrm{~mm}^{3}$ prior to mice being randomized to vehicle or C-PAC treatment groups. C-PAC was delivered by oral gavage $(100 \mu 1)$ at a concentration of $250 \mu \mathrm{g} /$ mouse, 6 days a week. Tumors were measured every 2-3 days throughout the experiment and mean tumor volume calculated using the following formula: $\pi / 6 x L x$ $W x H$ ( $L$, length; $W$, width; $H$, height). Increasing tumor size in the vehicle treated group required termination of the experiment on day 19. OE33 and JHAD1 cells did not generate tumors in this animal model, even when higher concentrations of cells were injected supporting that OE19 cells are phenotypically more aggressive.

\section{Statistical analysis}

Two-tailed unpaired Student's $t$-test or ANOVA were employed to test for statistically significant differences between treatment groups, followed by Tukey's post-hoc test. GraphPad Prism version 6.0 was utilized with $P<$ 0.05 considered statistically significant.

\section{ACKNOWLEDGMENTS}

We thank Dr. James R. Eshleman (Johns Hopkins University, Baltimore, MD) for sharing the JH-ESOAd1 cell line utilized in these studies.

\section{GRANT SUPPORT}

We thank the National Institutes of Health and National Cancer Institute for funding support via grant R01CA158319 and Advancing a Healthier Wisconsin (5220251) for equipment funds, both awarded to Laura A. Kresty.

\section{CONFLICTS OF INTEREST}

The authors have no potential conflicts of interest to disclose.

\section{REFERENCES}

1. Brown LM, Devesa SS, Chow WH. Incidence of adenocarcinoma of the esophagus among white Americans by sex, stage, and age. J Natl Cancer Inst. 2008; 100: 11841187.

2. Corley DA, Kubo A, Levin TR, Block G, Habel L, Rumore G, Quesenberry C, Buffler P. Race, ethnicity, sex and temporal differences in Barrett's oesophagus diagnosis: a large community-based study, 1994-2006. Gut. 2009; 58: 182-188.

3. American Cancer Society (2015) Cancer Facts and Figures. Atlanta: American Cancer Society; 2015.

4. Holmes RS, Vaughan TL. Epidemiology and pathogenesis of esophageal cancer. Semin Radiat Oncol. 2007; 17: 2-9.

5. Hampel H, Abraham NS, El-Serag HB. Meta-analysis: Obesity and the risk for gastroesophageal reflux disease and its complications. Ann Intern Med. 2005; 143: 199-211.

6. Washington DC: American Institute for Cancer Research; 2007. World Cancer Research Fund/American Institute for Cancer Research: Food, nutrition, physical activity, and prevention of cancer: A global perspective.

7. Kubo A, Levin TR, Block G, Rumore GJ, Quesenberry CP Jr, Buffler P, Corley DA. Dietary antioxidants, fruits, and vegetables and the risk of Barrett's esophagus. Am Gastroenterol. 2008; 103: 1614-1623.

8. Bravi F, Edefonti V, Randi G, Ferraroni M, La Vecchia C, Decarli A. Dietary patterns and upper aerodigestive tract cancers: an overview and review. Ann Oncol. 2012; 23: 3024-3948.

9. Howell AB, Botto H, Combescure C. Dosage effect on uropathogenic Escherichia coli anti-adhesion activity in urine following consumption of cranberry powder standardized for proanthocyanidin content: a multicentric randomized double blind study. BMC Infect Dis. 2010; 10: 94.

10. Krueger CG, Reed JD, Feliciano RP, Howell AB. Quantifying and characterizing proanthocyanidins in cranberries in relation to urinary tract health. Anal Bioanal Chem. 2013; 405: 4385-4395.

11. Foo LY, Lu Y, Howell AB, Vorsa N. The structure of 
cranberry proanthocyanidins which inhibit adherence of uropathogenic P-fimbriated Escherichia coli in vitro. Phytochemistry 2000; 54: 173-181.

12. Howell AB, Reed JD, Krueger CG, Winterbottom R, Cunningham DG, Leahy M. A-type cranberry proanthocyanidins and uropathogenic bacterial antiadhesion activity. Phytochemistry. 2005; 66: 2281-2291.

13. Kasper KL, Howell AB, Khoo C. A randomized doubleblind, placebo-controlled trial to assess the bacterial antiadhesion effects of cranberry extract beverages. Food Funct. 2015; 6: 1212-1217.

14. Pappas E, Schaich KM. Phytochemicals of cranberries and cranberry products: Characterization, potential health effects, and processing stability. Crit Rev Food Sci Nutr. 2009; 49: 741-781.

15. Neto CC. Cranberries: ripe for more cancer research? J Sci Food Agric. 2011; 91: 2303-2307.

16. Kresty LA, Howell AB, Baird M. Cranberry proanthocyanidins mediate growth arrest of lung cancer cells through modulation of gene expression and rapid induction of apoptosis. Molecules. 2011; 16: 2375-2390.

17. Kresty LA, Howell AB, Baird M. Cranberry proanthocyanidins induce apoptosis and inhibit acidinduced proliferation of human esophageal adenocarcinoma cells. J Agric Food Chem. 2008; 56: 676-680.

18. Kresty LA, Clarke J, Ezell K, Exum A, Howell AB, Guettouche T. MicroRNA alterations in Barrett's esophagus, esophageal adenocarcinoma, and esophageal adenocarcinoma cell lines following cranberry extract treatment: Insights for chemoprevention. J Carcinog. 2011; 10: 34

19. Déziel B, MacPhee J, Patel K, Catalli A, Kulka M, Neto C, Gottschall-Pass K, Hurta R. American cranberry (Vaccinium macrocarpon) extract affects human prostate cancer cell growth via cell cycle arrest by modulating expression of cell cycle regulators. Food Funct. 2012; 3: 556-564.

20. Kim KK, Singh AP, Singh RK, Demartino A, Brard L, Vorsa N, Lange TS, Moore RG. Anti-angiogenic activity of cranberry proanthocyanidins and cytotoxic properties in ovarian cancer cells. Int J Oncol. 2012; 40: 227-235.

21. Liu M, Lin LQ, Song BB, Wang LF, Zhang CP, Zhao JL, Liu JR. Cranberry phytochemical extract inhibits SGC-7901 cell growth and human tumor xenografts in Balb/c nu/nu mice. J Agric Food Chem. 2009; 57: 762-768.

22. Evans S, Dizeyi N, Abrahamsson PA, Persson J. The effect of a novel botanical agent TBS-101 on invasive prostate cancer in animal models. Anticancer Res. 2009; 29: 39173924.

23. Ferguson PJ, Kurowska EM, Freeman DJ. In vivo inhibition of growth of human tumor lines by flavonoid fractions from cranberry extract. Nutr Cancer. 2006; 56: 86-94.

24. Boateng J, Verghese M, Shackelford L, Walker LT, Khatiwada J, Ogutu S, Williams DS, Jones J, Guyton M,
Asiamah D, Henderson F, Grant L, DeBruce M, et al. Selected fruits reduce azoxymethane (AOM)-induced aberrant crypt foci (ACF) in Fisher 344 male rats. Food Chem Toxicol. 2007; 45: 725-732.

25. Prasain JK, Jones K, Moore R, Barnes S, Leahy M, Roderick R, Juliana MM, Grubbs CJ. Effect of cranberry juice concentrate on chemically-induced urinary bladder cancers. Oncol Rep. 2008; 19: 1565-1570.

26. Jenkins GJ, Harries K, Doak SH, Wilmes A, Griffiths AP, Baxter JN, Parry JM. The bile acid deoxycholic acid (DCA) at neutral $\mathrm{pH}$ activates NF- $\mathrm{KB}$ and induces IL-8 expression in oesophageal cells in vitro. Carcinogenesis. 2004; 25 : 317-323.

27. Bernstein H, Berstein C, Payne CM, Dvorak K. Bile acids as endogenous etiologic agents in gastrointestinal cancer. World J Gastroenterol. 2009; 15: 3329-3340.

28. Dvorakova K, Payne CM, Ramsey L, Bernstein H, Holubec H, Chavarria M, Bernstein C, Sampliner RE, Riley C, Prasad A, Garewal H. Apoptosis resistance in Barrett's esophagus:ex vivo bioassay of live stressed tissues. Am J Gastroenterol. 2005; 100: 424-431.

29. Goldman A, Chen HD, Roesly HB, Hill KA, Tome ME, Dvorak B, Bernstein H, Dvorak K. Characterization of squamous esophageal cells resistant to bile acids at acidic $\mathrm{pH}$ : implication for Barrett's esophagus pathogenesis. Am J Physiol Gastrointest Liver Physiol. 2011; 300: G292-302.

30. Yen CJ, Izzo JG, Lee DF, Guha S, Wei Y, Wu TT, Chen CT, Kuo HP, Hsu JM, Sun HL, Chou CK, Buttar NS, Wang $\mathrm{KK}$, et al. Bile acid exposure up-regulates tuberous sclerosis complex 1/mammalian target of rapamycin pathway in Barrett's-associated esophageal adenocarcinoma. Cancer Res. 2008; 68: 2632-2640.

31. Abdel-Latif MM, Kelleher D, Reynolds JV. Molecular mechanisms of constitutive and inducible NF-kappaB activation in oesophageal adenocarcinoma. Eur J Cancer. 2015; 51: 464-472.

32. Boonstra JJ, Marion RV, Beer DG, Lin L, Chaves P, Ribeiro C, Pereira AD, Roque L, Darnton SJ, Altorki NK, Schrump DS, Klimstra DS, Tang LH, et al. Verification and unmasking of widely used human esophageal adenocarcinoma cell lines. J Natl Cancer Inst. 2010; 102: 271-274.

33. Reid BJ, Prevo LJ, Galipeau PC, Sanchez CA, Longton G, Levine DS, Blount PL, Rabinovitch PS. Predictors of progression in Barrett's esophagus II: baseline 17p (p53) loss of heterozygosity identifies a patient subset at increased risk for neoplastic progression. Am J Gastroenterol. 2001; 96: 2839-2848.

34. Murray L, Sedo A, Scott M, McManus D, Sloan JM, Hardie LJ, Forman D, Wild CP. TP53 and progression from Barrett's metaplasia to oesophageal adenocarcinoma in a UK population cohort. Gut. 2006; 55: 1390-1397.

35. Fichter CD, Herz C, Münch C, Opitz OG, Werner M, Lassmann S. Occurrence of multipolar mitoses and 
association with Aurora-A/-B kinases and p53 mutations in aneuploid esophageal carcinoma cells. BMC Cell Biol. 2011; 12: 13 .

36. Alvarez H, Koorstra JB, Hong SM, Boonstra JJ, Dinjens WN, Foratiere AA, Wu TT, Montgomery E, Eshleman JR, Maitra A. Establishment and characterization of a bona fide Barrett esophagus-associated adenocarcinoma cell line. Cancer Biol Ther. 2008; 7: 1753-1755.

37. Feng Z, Zhang H, Levine AJ, Jin S. The coordinate regulation of the $\mathrm{p} 53$ and mTor pathways in cells. Proc Natl Acad Sci USA. 2005; 102: 8204-8209.

38. Rosenbluth JM, Mays DJ, Pino MF, Tang LJ, Pientenpol JA. A gene signature based approach identifies mTOR as a regulator of p73. Mol Cell Biol. 2008; 28: 5951-5964.

39. Son Y, Cheong YK, Kim NH, Chung HT, Kang DG, Pae HO. Mitogen-Activated Protein Kinases and Reactive Oxygen Species: How Can ROS Activate MAPK Pathways? J Signal Transduct. 2011; 2011: 792639.

40. Kirkland JB. Poly ADP-ribose polymerase-1 and health. Exp Biol Med. 2010; 235: 561-568.

41. Halicka HD, Zhao H, Li J, Lee YS, Hsieh TC, Wu JM, Darzynkiewicz Z. Potential anti-aging agents suppress the level of constitutive mTOR- and DNA damage- signaling. Aging (Albany, NY). 2012; 4: 952-965.

42. Yoon JH, Ahn SG, Lee BH, Jung SH, Oh SH. Role of autophagy in chemoresistance: regulation of the ATMmediated DNA-damage signaling pathway through activation of DNA-PKcs and PARP-1. Biochem Pharmacol. 2012; 83: 747-757.

43. Deverman BE, Cook BL, Manson SR, Niederhoff RA, Langer EM, Rosová I, Kulans LA, Fu X, Weinberg JS, Heinecke JW, Roth KA, Weintraub SJ. Bcl-xL deamidation is a critical switch in the regulation of the response to DNA damage. Cell. 2002; 111: 51-62.

44. Zhao R, Oxley D, Smith TS, Follows GA, Green AR, Alexander DR. DNA damage-induced Bcl-xL deamidation is mediated by NHE-1 antiport regulated intracellular $\mathrm{pH}$. PLoS Biol. 2007; 5: 39-53.

45. Reid BJ, Li X, Galipeau P, Vaughen TL. Barrett's oesophagus and oesophageal adenocarcinoma: time for a new synthesis. Nat Reviews Cancer. 2010; 10: 87-101.

46. Scarlatti F, Maffei R, Beau I, Codogno P, Ghidoni R. Role of non-canonical Beclin 1-independent autophagy in cell death induced by resveratrol in human breast cancer cells. Cell Death Differ. 2008; 15: 1318-1329.

47. Niso-Santano M, Bravo-San Pedro JM, Maiuri MC, Tavernarakis N, Cecconi F, Madeo F, Codogno P, Galluzzi L, Kroemer G. Novel inducers of BECN1-independent autophagy: cis-unsaturated fatty acids. Autophagy. 2015; 11: 575-577.

48. Paterson AL, Shannon NB, Lao-Sirieix P, Ong CA, Peters CJ, O'Donovan M, Fitzgerald RC. A systematic approach to therapeutic target selection in oesophago-gastric cancer. Gut. 2013; 62: 1415-1424.
49. Tasioudi KE, Sakellariou S, Levidou G, Theodorou D, Michalopoulos NV, Patsouris E, Korkolopoulou P, Saetta AA. Immunohistochemical and molecular analysis of PI3K/ AKT/mTOR pathway in esophageal carcinoma. APMIS. 2015; 123: 639-647.

50. Prins MJ, Verhage RJ, Ruurda JP, ten Kate FJ, van Hillegersberg R. Over-expression of phosphorylated mammalian target of rapamycin is associated with poor survival in oesophageal adenocarcinoma: a tissue microarray study. J Clin Pathol. 2013; 66: 224-228.

51. Hildebrandt MA, Yang H, Hung MC, Izzo JG, Huang M, Lin J, Ajani JA, Wu X. Genetic variations in the PI3K/ PTEN/AKT/mTOR pathway are associated with clinical outcomes in esophageal cancer patients treated with chemoradiotherapy. J Clin Oncol. 2009; 27: 857-871.

52. Lao-Sirieix P, Lovat L, Fitzgerald RC. Cyclin A immunocytology as a risk stratification tool for Barrett's esophagus surveillance. Clin Cancer Res. 2007; 13: 659665.

53. von Holzen U, Chen T, Boquoi A, Richter JE, Falk GW, Klein-Szanto AJ, Cooper H, Litwin S, Weinberg DS, Enders GH. Evidence for DNA damage checkpoint activation in Barrett esophagus. Transl Oncol. 2010; 3: 33-42.

54. Roesly HB, Khan MR, Chen HD, Hill KA, Narendran N, Watts GS, Chen X, Dvorak K. The decreased expression of Beclin-1 correlates with progression to esophageal adenocarcinoma: the role of deoxycholic acid. Am J Physiol Gastrointest Liver Physiol. 2012; 302: G864-G872.

55. Chen Y, Lu Y, Lu C, Zhang L. Beclin-1 expression is a predictor of clinical outcome in patients with esophageal squamous cell carcinoma and correlated to hypoxiainducible factor (HIF)-1 $\alpha$ expression. Pathol Oncol Res. 2009; 15: 487-493.

56. Dho SH, Deverman BE, Lapid C, Manson SR, Gan L, Riehm JJ, Aurora R, Kwon KS, Weintraub SJ. Control of cellular Bcl-xL levels by deamidation-regulated degradation. PLoS Biol. 2013; 11: e1001588.

57. Daniel VC, Marchionni L, Hierman JS, Rhodes JT, Devereux WL, Rudin CM, Yung R, Parmigiani G, Dorsch M, Peacock CD, Watkins DN. A primary xenograft model of small-cell lung cancer reveals irreversible changes in gene expression imposed by culture in vitro. Cancer Res. 2009; 69:3364-73. 